\title{
INFLATION TARGETING AND AN OPTIMAL TAYLOR RULE FOR AN OPEN ECONOMY: EVIDENCE FOR COLOMBIA 1990-2011*
}

\author{
EDGAR VILLA ${ }^{* *}$ \\ MARTHA A. MisAs ${ }^{* * *}$ \\ Andrés F. Giraldo ${ }^{* * * *}$
}

\begin{abstract}
An optimal monetary policy Taylor rule is developed for an open economy, which we then estimate following a Markov regime-switching model for quarterly data from Colombia during 1990-2011. We find two opposite monetary regimes characterized by different policy rules: until October 2000 the Central Bank of Colombia reacted only statistically to output gap changes while after October 2000, when inflation targeting was officially adopted, monetary policy reacted only statistically to changes in the inflation rate. The latter regime is consistent with the Taylor principle as shown analytically and verified empirically by a unit root test for a Markov regime-switching model.
\end{abstract}

JEL classification: C24, E42, E52, E58, N16

Keywords: Optimal Taylor rule, inflation targeting, Taylor principle, Markov switching

\section{INTRODUCTION}

The econometric assessment of monetary rules such as Taylor's rule (1993) has become an important field of study in the modern monetary policy literature, as that paper stimulated a series of theoretical and empirical studies with varying objectives. ${ }^{1}$ Issues such as the optimality, robustness, performance, and efficiency of monetary rules are the main focus of this research agenda. Conducting monetary policy according to simple rules that help achieve policy objectives, such as inflation targeting, has become

\footnotetext{
* The authors are grateful for comments made on an early version of this paper by Hernando Vargas, Andrés González, Franz Hamann and Andrés Velasco.

** Corresponding author. Associate Professor, International School of Economic and Administrative Sciences at Universidad de La Sabana, Campus del Puente Común, Chía-Colombia. Email: edgar.villa@ unisabana.edu.co.

*** Associate Professor in the Economics Department of Pontificia Universidad Javeriana Bogotá, Edificio Gabriel Giraldo, piso 7mo, Bogotá-Colombia.

**** Assistant Professor in the Economics Department of Pontificia Universidad Javeriana Bogotá, Edificio Gabriel Giraldo, piso 7mo, Bogotá-Colombia.

1. Taylor (1999) presents various studies that provide empirical evidence on the efficiency and robustness of different monetary rules when they are used to guide the decisions of the monetary authority.
} 
a crucial issue for price and macroeconomic stability, especially in developing economies, as it increases the transparency and credibility of the monetary authority (Woodford, 2003a). This prevents time inconsistencies in monetary policy rules (Kydland and Prescott, 1977; Barro and Gordon, 1983) and also provides transparency for the public (Svensson, 2000, 2008 and 2011).

Empirical assessment of monetary rules is useful from both the operational and academic points of view. In terms of operations, it provides a method for describing the behavior of central banks "as if" they use monetary rules, while from an academic point of view, it helps in analyzing the optimal behavior of these monetary rules. A key concept that emerges in the literature starting with Taylor (1993) is the so-called Taylor principle. According to this principle, the monetary authority increases the intervention interest rate more than proportionally to inflationary pressures, in order to lower inflation expectations and reach a long-term inflation target. ${ }^{2}$ Murray et al. (2008) have argued that a central bank that systematically satisfies the Taylor principle generates a stationary inflation rate as a time series; in other words, it should not exhibit a stochastic trend or a unit root behavior. Thus, the literature has linked inflation targeting with simple monetary rules in which a central bank changes the intervention interest rate of an economy according to inflation deviations from a target as an appropriate monetary intervention mechanism (Clarida et al., 1998, 1999, 2000) ${ }^{3}$ which should satisfy the so-called Taylor principle.

It is important to note that Taylor (1993) presents his rule as a simple ad hoc rule, in the sense that it is not derived from a macroeconomic optimization model. However, subsequent papers deduce monetary rules in the style of Taylor based on the development of a general model in which agents and the monetary authority are optimizing ${ }^{4}$. The purpose of this paper is to find a monetary rule, in the style of Taylor, that is derived from an optimization problem of a central bank in an open economy, where it takes into account deviations of inflation

2. See Walsh (2010) and Woodford (2003a).

3. According to Mishkin (1999), central banks have followed different monetary strategies whose common denominator is the definition of a nominal anchor to "tie" agents' inflation expectations. The strategies most widely used by central banks are: 1) monetary aggregate regimes, whose nominal anchor is monetary supply growth (called monetarism); 2) exchange rate regimes, in which the nominal anchor is the exchange rate chosen within an exchange rate band; and, 3) a target inflation rate, where the anchor is the inflation forecast (Svensson and Woodford, 2003) or the medium- to long-term inflation target.

4. Orphanides (2008) presents some functional forms based on the Taylor rule. 
from its target, economic cycles represented by the output gap, as well as the desire to smooth out the intervention rate and the deviation of the real exchange rate relative to a long-term target. The structure of the theoretical model developed is based on traditional foundations in the literature: a quadratic central bank loss function, a Phillips curve and an aggregate demand equation ${ }^{5}$. The optimal intervention rule for an open economy is found through an optimization procedure "as if" followed by the bank. A key analytical result we find is that the optimal Taylor rule for an open economy is satisfied only if the inflation rate is not a highly persistent time series or does not exhibit stochastic trend (unit root) behavior.

Once the optimal Taylor rule is obtained in its reduced form, it leads to an econometric model that is estimated as a Markov-switching model for Colombia between 1990 and 2011. This methodology seems appropriate since the Bank of the Republic (BR) of Colombia adopted an explicit inflation targeting policy halfway through this period, in October 2000. Importantly, the empirical methodology allows estimation of whether there was a monetary policy regime switch in the BR's behavior, consistent with a change in the parameters of the optimal Taylor rule with respect to the inflation rate and/or the output gap due to the explicit adoption of the inflation targeting monetary regime in October 2000, without having to specify exogenously the date of the possible structural regime switch. Empirical evidence is found that there were two monetary policy states or regimes in which the BR's behavior, in terms of the optimal Taylor rule, is the opposite of the way in which the intervention interest rate reacted to changes in the inflation rate and the output gap. In one regime, which prevailed prior to October 2000 and is labeled the regime with no inflation targeting (NIT), the BR maintained a policy in which the intervention interest rate reacted statistically solely to changes in the output gap; in the other regime, which prevailed after October 2000 and is labeled the regime with inflation targeting (IT), the intervention interest rate reacted statistically only to changes in the inflation rate.

Statistical evidence is also found that the Taylor principle was satisfied only in the IT regime. According to our analytical results, which confirm analytically Murray et al.'s (2008) insight, this implies that

5. Although a Phillips curve and an aggregate demand curve are not generated from an optimization exercise within our framework, it is possible to demonstrate that they come from the idea of consumer and firm maximization. See Walsh (2010) and Woodford (2003b). 
in the NIT regime the inflation rate could be a time series with a stochastic trend or unit root while in the IT regime, it should be a stationary time series. Consequently, a unit root test is performed on the inflation rate series for the time period under study, also within a Markov regime-switching model, to indirectly verify whether the Taylor principle is satisfied, consistent with the inflation-targeting policy instituted after October 2000. Empirical evidence is found that the inflation rate is a time series with a unit root in the NIT regime that prevailed before October 2000, while it is stationary in the post-October 2000 IT regime. This indirectly verifies that adoption of the IT monetary policy regime produced a structural change in the way the BR conducts monetary policy after 2000. Our combined results support the idea that an inflation targeting policy is beneficial for small countries like Colombia because it allows central banks to control inflationary shocks, steadily maintaining the inflation rate at low levels in a credible way.

This article provides two original contributions to the literature regarding monetary rules. First, it develops an optimal monetary rule in the style of Taylor for an open economy that takes into account both deviations of inflation from its target and economic cycles represented by the output gap, as well as the desire to smooth out the intervention rate and the deviation of the real exchange rate relative to a long-term target. This is an important contribution because most of the empirical literature is based on an ad hoc monetary rule that is not necessarily deduced optimally in a theoretical framework consistent with the interests of central banks. In addition, the theoretical literature on monetary rules usually focuses on rules for closed economies, considering countries such as the United States. This does not appear to be suitable for understanding the monetary policy of small and open economies such as Colombia. The key result is that we show that the Taylor principle cannot be satisfied in the optimal Taylor rule for an open economy if the inflation rate is a highly persistent time series displaying a unit root or stochastic trend.

The second contribution is that the theoretical optimal monetary rule is estimated using a Markov-switching methodology for an underdeveloped economy like Colombia. This is an important contribution, especially for Latin America, because this methodology is rarely used in the literature for countries in this part of the world. Exceptions to this trend are Kuzin (2004) which studies Germany's Bundesbank and Murray et al. (2008) which studies the U.S. Federal Reserve also using 
a Markov-switching methodology. More importantly we believe this methodology models regime switches endogenously, which seems more suitable than the typical methodology of imposing a regime switch exogenously as in Orphanides (2000).

The article is organized as follows: In Section 2 we present a review of the literature on monetary rules, while Section 3 develops the theoretical model that leads to the optimal Taylor rule for an open economy. Section 4 presents a Markov-switching econometric model that is estimated for the optimal Taylor rule developed. Section 5 contains a description of the information used in the econometric model. Section 6 provides the empirical results, while Section 7 concludes.

\section{LITERATURE REVIEW}

The appearance of the concept of rational expectations and its subsequent use in macroeconomic theory and policy changed how the formation of agent expectations is modeled. Kydland and Prescott (1977) showed theoretically the presence of an inflationary bias due to the existence of dynamically inconsistent economic policies. Subsequent to their work, the main theoretical concern has focused on how to eliminate that inflationary bias through monetary rules. Increasing importance has been given to ideas about the independence of the monetary authority, reputation-building in dynamic models, following transparent monetary rules, and the credibility of monetary policy announcements to prevent dynamic inconsistencies in discretionary monetary policy. ${ }^{6}$ The work of Taylor (1993) is important to monetary policy literature because it makes operational the theoretical debate on rules versus discretion. In that seminal work, the author provides a first approximation to systematic behavior of monetary policy, using a simple, ad hoc monetary policy rule aimed at approaching the real behavior of the Federal Reserve's intervention interest rate "as if" the Fed actually followed that rule. ${ }^{7}$ Specifically, Taylor presents the rule as follows:

$$
i=\pi+g x+h\left(\pi-\pi^{*}\right)+r
$$

6. For more details on this topic, a good reference is Walsh (2000).

7. Traditionally, assessment of monetary policy has implicitly assumed rules of behavior set in the monetary instruments, such as a fixed growth rate of monetary supply (Friedman, 1968). However, until Taylor (1993) monetary rules were not viewed as reaction functions of monetary instruments. The main reasons are that it is difficult for a central bank to follow mechanical rules of behavior and it is also quite implausible that a central bank would maintain a fixed instrument for a certain period of time. 
where $i$ is the short-term interest rate, $\pi$ is the inflation rate expressed as the percentage change in the price index, $\pi^{*}$ is the inflation target, $x$ is the percentage deviation of real output from potential output, $g$ is the interest rate response to changes in the output gap, $1+h$ is the response to changes in inflation relative to the target and $r$ is the real interest rate. The values that characterize the Federal Reserve's behavior according to Taylor are the following: $g=0.5$, $h=0.5, \pi^{*}=2$ and $r=2 .{ }^{8}$ The Taylor rule, initially established in an ad hoc fashion and which is shown as Equation (1), is used to closely describe the trajectory of the U.S. federal funds rate for the period 1987-1992. ${ }^{9}$

Later studies attempt to show that the rule is also optimal in the framework of an equilibrium macroeconomic model, ${ }^{10}$ and specifically, they have delved deeper into the design of monetary rules, in order to analyze their performance in terms of efficiency, robustness, and optimality. ${ }^{11}$ It is worth mentioning that the Taylor rule has consistently been the way of thinking behind the strategy of inflation targeting. ${ }^{12}$ The differences in the specification of the various rules in the style of Taylor are mainly associated with whether the inflation gap is measured using the inflation target or inflation expectations ${ }^{13}$ and also with the variables included in the equation used to determine the value of the instrument.

Orphanides (2008) has argued, in addition to the original Taylor rule, that other types of reaction functions have been designed that are inspired by Taylor's exercise (1993). The common characteristic of these rules is the response (optimal in many cases) of the interest

8. The idea behind Equation (1) is that the bank intervenes in the monetary market by changing the interest rate if real output diverges from potential output or inflation diverges from its target. If there are no cycles $(x=0)$ or inflationary pressures $\left(\pi=\pi^{*}\right)$, the objective is for the intervention rate to approach its long-term level, that is, $i=\pi+r$. Taylor presents the derivation of his rule intuitively: Given that the velocity of money depends on the interest rate $(i)$, it is possible to find a relationship between $i$ and price level $P$ and real output $Y$. Exogenous changes in the monetary supply or velocity displace this relationship. This relationship will be maintained over time regardless of whether the money stock is growing at a fixed rate, although the money stock will respond systematically to interest rate and output changes. The response of money will be reflected in the change in parameters of the relationship. 9. Although Taylor (1993) is not attempting to define the Federal Reserve's "exact" rule, the equation describes a reaction function "as if" the monetary authority were following that rule, even though the Fed has never explicitly adopted an inflation-targeting policy regime.

10. Taylor's work not only stimulated the assessment of monetary rules, but also the search for optimal rules in a more general framework.

11. A sample of studies in this tradition of the literature can be found in Taylor (1999).

12. See Clarida et al. (1998); Clarida et al. (1999); Clarida et al. (2000); Rudebusch and Svensson (1999); Svensson (1999); and Svensson (1999), among others.

13. As in the works of Clarida, Gali and Gertler. 
rate to the inflationary gap (the deviation of the inflation rate from its expected value or target) and to the output gap. Recently, other factors have been included that could influence the central bank's response, such as the intervention interest rate with a one-period $\operatorname{lag}^{14}$, the exchange rate ${ }^{15}$ or the price of assets (Bernanke and Gertler, 2000; Bernanke and Gertler, 2001; Carlstrom and Fuerst, 2007). In light of this, it has been important in the literature to quantitatively assess how the rules perform (Svensson, 2011), as well as the reaction of the central bank "as if" it were to conduct monetary policy using the reaction function that the Taylor rule prescribes or that which results from the specification of the economic model. ${ }^{16}$

The definition of monetary rules based on observation and empirical evaluation has been traditional in the literature on rules in the style of Taylor. These rules are not necessarily optimal monetary rules in the sense of being derived from an optimization problem; rather, they are simple, ad hoc rules concerning the way in which monetary policy is carried out. The literature has generated a set of optimal and nonoptimal monetary rules. This paper focuses on an optimal Taylor rule because we believe that it is important that the reaction function of a central bank come from a theoretical model of optimization that involves the usual concerns that a central bank of a small, open economy has in maintaining macroeconomic stability. From a theoretical point of view, there is another characteristic that a Taylor rule must satisfy (original, ad hoc, or optimal) and which is related to the size of the coefficients, particularly the coefficient that accompanies the inflationary gap or aversion to inflation (parameter $1+h$ of Equation (1)). As shown in Woodford (2003, Chap. 2), a necessary condition is that it has a value greater than one so that the

14. To capture the central bank's desire to smooth out and avoid large movements in interest rates. For a detailed discussion, see Clarida et al. (1998), Woodford (2003, Chap 4), Woodford (2003), and Walsh (2010, Chap. 8).

15. See Ball (1999), Svensson (2000), and Taylor (2001). Giraldo et al. (2011) assess a monetary rule in which they include the real exchange rate, with a one- or two-period lag, as well as the smoothing of the interest rate for a closed economy, and they find that the coefficients associated with the exchange rate are not significant for Colombia between 1990 and 2010. For their part, Batini et al. (2003) and Batini et al. (2009) evaluate a series of monetary rules to determine their efficiency and robustness in a macroeconomic model. The common denominator of the rules involved international variables, such as the inclusion of real exchange rate levels (lagging and contemporary) as well as real devaluation. One of the rules includes the trade balance. The articles show that improvements in wellbeing due to inclusion of the exchange rate are marginal, although they do not analyze whether the monetary authority takes that variable into account when making policy decisions.

16. This type of assessment has been common for the United States: Taylor (1993); Taylor (1999a); Clarida et al. (1998); Clarida et al. (1999); Clarida et al. (2000), among others. Recently, similar exercises have been performed for other countries such as Germany (Kuzin, 2004) and Colombia (López, 2004; Pérez, 2005; Giraldo, 2008; Bernal and Tautiva, 2011; Giraldo et al., 2011). 
central bank's intervention will significantly affect the interest rate and thus investment and consumption will react to the change made by the monetary authority. This characteristic of monetary rules is known as the Taylor principle and in our view, an inflation-targeting policy should satisfy this principle.

Recently, the literature has addressed the possibility that a central bank may show an asymmetrical reaction to changes in variables that affect the interest rate in the monetary rule (traditionally the inflation gap and output gap), which would reflect different monetary positions for reaching the price stabilization objective. For example, Kuzin (2004) shows that the parameters of an ad hoc monetary reaction function, particularly that of aversion to inflation, have varied over time, and provides evidence for Germany's Bundesbank that when the inflation gap is positive, the Bundesbank reacts more strongly in raising interest rates than when the gap is negative.

Kuzin finds this asymmetrical reaction by using a Kalman filter as well as estimating with a Markov-switching methodology, where the parameters vary according to the economic regime. Furthermore, Kuzin estimates a simple Taylor rule (ad hoc, modified) with interestrate smoothing. The main finding is that aversion to inflation is not constant and shows large and sudden changes during the period in which a monetary aggregates tracking strategy is used. In particular, Kuzin finds periods of high aversion and low aversion to inflation, in which the former are those coinciding with fulfillment of the Taylor principle. Despite the strong central bank tradition of the Bundesbank, there have been periods in which aversion is low and therefore the Taylor principle is not fulfilled. From a practical point of view, the Bundesbank follows a policy that accommodates changes in inflation during these periods.

On the other hand, Murray et al. (2008) use a simple macroeconomic model to argue that when the inflation rate follows a stationary process, it is because the central bank follows the Taylor principle, given that the monetary authority reacts strongly to inflationary pressures, driving inflation towards its long-term target. These authors show that the way in which the Federal Reserve drives monetary policy is not always geared toward stabilizing inflation, and they suggest that it is more common to face diverse regimes in which the parameters reflect different preferences of the central bank for stabilizing output or inflation. The authors estimate a Markov-switching model to show 
that U.S. monetary policy can be described as one of two states: one in which the Taylor principle is fulfilled and the inflation rate is stationary, and another in which the Taylor principle is not fulfilled and the inflation rate follows a unit root process.

The findings of Murray et al. (2008) contrast with those of Clarida et al. (1998), Clarida et al. (2000) and Orphanides (2000), which report, for the Federal Reserve, stability of parameters in periods that have been identified as inflation-stabilizing. What is novel about Murray et al. (2008) is that they find the break points or regime-switch points endogenously, using the Markov-switching methodology. As they argue, it is very risky to define, a priori, the periods of time in which one or another monetary regime is believed to function, based only on history. In this sense, this article follows Murray et al. (2008) in that the regime-switching dates are allowed to be defined endogenously even for the case of Colombia, which adopted the target inflation rate monetary policy explicitly in October 2000. However, since the 1990s the central bank of Colombia had been implicitly implementing some measures that are, to a certain extent, compatible with an inflation targeting regime.

Based on all this, this article studies an optimal Taylor rule in the framework of a small, open economy such as Colombia's, which has the following characteristics: i) it responds to deviations in inflation and the output gap (as the original rule; ii) it involves the central bank's desire to smooth the interest rate; and iii) it includes the exchange rate (or variables related to it). The model that we present below is innovative in that it includes variables from other countries that could affect the monetary policy of a small, open economy, unlike what has usually been done in the literature with use of the original Taylor rule, which is designed for a (virtually) closed economy such as the United States.

\section{MODEL}

\subsection{Basic assumptions}

Consider the central bank of a small, open economy that takes as given an aggregate intertemporal IS curve as follows:

$$
x_{t}=E_{t} x_{t+1}+\delta x_{t-1}-\sigma\left(r_{t}-r^{n}\right)+\delta^{*} x_{t}^{*}+\alpha_{1} e_{t}+\varepsilon_{1 t}
$$


and an aggregate supply curve as follows:

$$
\pi_{t}=\beta E_{t} \pi_{t+1}+\gamma \pi_{t-1}+k x_{t}+\alpha_{2} e_{t}+\varepsilon_{2 t}
$$

where $x$ denotes the log of the output gap for the domestic economy while $x^{*}$ denotes the output gap for the country that is the trading partner of the domestic economy, the operator $\mathrm{E}_{t}(\cdot)$ is the expected value in period $t$ of the variable in period $t+1$ using all observable information until period $t$, and $r$ denotes the interest rate that satisfies:

$$
r_{t}=i_{t}-E_{t} \pi_{t+1}
$$

which is the Fisher equation, where $i$ denotes the logarithm of the nominal (short-term) interest rate and $\pi$ is the log of the inflation rate. That said, the variable $r^{n}$ in Equation (2) represents the longterm level of the logarithm of the real interest rate, which is assumed to be exogenously determined in the domestic economy. The variable $e$ in equations (2) and (3) denotes the log of the real exchange rate, which is defined as

$$
e_{t} \equiv R_{t}-p_{t}^{*}-p_{t}
$$

where $R$ is the logarithm of the nominal exchange rate, $p^{*}$ is the logarithm of the price level of the trading partner, and $p$ is the logarithm of the price level of the domestic economy. We assume that a small open economy must necessarily satisfy the condition of interest rate parity given by:

$$
i_{t}-i_{t}^{*}=E_{t} R_{t+1}-R_{t}+\varphi_{t}
$$

where $i^{*}$ is the logarithm of the nominal interest rate of the trading partner and $\varphi$ is the risk premium of the domestic economy relative to the trading partner. The imposition of this parity condition follows Svensson (2000) who argues that a truly open economy must satisfy this condition. The risk premium $\varphi$ incorporates any type of disturbance exogenous to the exchange rate, including changes in portfolio preferences, credibility effects, etc. Using Equation (5) we can describe this parity condition in terms of the logarithm of 
the real exchange rate ${ }^{17}$ given the definitions $E_{t} p_{t+1}-p_{t} \equiv \pi_{t}$ and $E_{t} p_{t+1}^{*}-p_{t}^{*} \equiv \pi_{t}^{*}$ which generates the following form, lagged one period:

$$
e_{t}-e_{t-1}=\left(i_{t-1}-i_{t-1}^{*}\right)-\left(\pi_{t}-\pi_{t}^{*}\right)-\varphi_{t-1}
$$

The parameters of the equations described above are assumed to satisfy the following: $\sigma>0, \delta \in(0,1), \delta^{*}>0, \gamma \in[-1,1], \beta \in[0,1], k>0$, while $\alpha_{1}$ and $\alpha_{2}$ can be, but aren't necessarily, positive. The terms $\varepsilon_{1}$ and $\varepsilon_{2}$ in (2) and (3) denote, respectively, the demand and supply disturbances, which are assumed to be i.i.d. normally distributed disturbances with a zero mean and variances $\sigma_{1}^{2}$ and $\sigma_{2}^{2}$, respectively.

We assume that the country that is the trading partner of the open domestic economy is an economy that follows a Taylor rule for a closed economy with the form:

$$
i_{t}^{*}=r^{n^{*}}+\eta_{x} x_{t}^{*}+\eta_{\pi} \pi_{t}^{*}+\varepsilon_{t}^{*}
$$

where $\eta_{x} \neq 0, \eta_{\pi}>1$ and $\varepsilon_{t}^{*} \sim i i d\left(0, \sigma^{* 2}\right)$. In addition, we assume that the expectations of the open economy's central bank concerning $x_{t}^{*}$, $\pi_{t}^{*}$ and $\varphi_{t}$ are stable $\operatorname{AR}(2)$ stochastic processes where

$$
\begin{aligned}
& E_{t} x_{t+1}^{*}=\rho_{x, 1} x_{t}^{*}+\rho_{x, 2} x_{t-1}^{*} \\
& E_{t} \pi_{t+1}^{*}=\rho_{\pi, 1} \pi_{t}^{*}+\rho_{\pi, 2} \pi_{t-1}^{*}+\bar{\pi}^{*} \\
& E_{t} \varphi_{t+1}=\rho_{\varphi, 1} \varphi_{t}+\rho_{\varphi, 2} \varphi_{t-1}+\bar{\varphi}
\end{aligned}
$$

such that $\bar{\pi}^{*} \geq 0, \bar{\varphi} \geq 0$ and the coefficients $\rho_{h, i}$ for $h=x^{*}, \pi^{*}, \varphi$ and $i=1,2$ satisfy $\left|\rho_{h, i}\right|<1, \rho_{h, 1}+\rho_{h, 2}<1, \rho_{h, 2}<1+\rho_{h, 1},\left|\rho_{h, 2}\right|<1$.

We also assume that the central bank has a loss function represented by

$$
\begin{aligned}
\frac{\mathcal{L}_{t}}{2}= & \left(\pi_{t}-\bar{\pi}\right)^{2}+\lambda_{1} x_{t}^{2}+\lambda_{2}\left(e_{t}-e^{n}\right)^{2} \\
& +\lambda_{3}\left(e_{t-1}-e_{t-1}\right)^{2}+\lambda_{4}\left(i_{t}-i_{t-1}\right)^{2}
\end{aligned}
$$

17. Take Equation (5) which is forwarded one period such that $E_{t} e_{t+1}=E_{t} R_{t+1}+E_{t} p_{t+1}^{*}-E_{t} p_{t+1}$ and then substract $e_{t}=R_{t}+p_{t}^{*}-p_{t}$, which generates $E_{t} e_{t+1}-e_{t}=E_{t} R_{t+1}-R_{t}+E_{t} p_{t+1}^{*}-p_{t}^{*}$ $-E_{t} p_{t+1}+p_{t}$. Therefore, $E_{t} R_{t+1}-R_{t}=E_{t} e_{t+1}-e_{t}-\left(E_{t} p_{t+1}^{*}-p_{t}^{*}\right)+\left(E_{t} p_{t+1}-p_{t}\right)$. Replacing this equation in (6) generates $i_{t}-i_{t}^{*}=E_{t} e_{t+1}-e_{t}+\left(E_{t} p_{t+1}-p_{t}\right)-\left(E_{t} p_{t+1}^{*}-p_{t}^{*}\right)+\varphi_{t}$. 
where $\lambda_{i}=1, . ., 4$ are nonnegative parameters. The first two terms are common to the majority of monetary rules, where $\lambda_{1}$ reflects the weight of the output gap relative to the weight of one in inflation's deviation from its target $\bar{\pi}$. Having said that, the term associated with $\lambda_{2}$ reflects the weight that the central bank of the domestic economy assigns to the difference between its real exchange rate and the long run target rate $e^{n}$ (which may be explicit or implicit for the central bank). This is justified in part by the fact that small, open economies have had explicit exchange rate bands (publicly known) or even implicit ones (not publicly known), as in Colombia. Moreover, we consider that the central bank of this small open economy intervenes when there are strong fluctuations in the real exchange rate from one period to another, which is reflected in the weight $\lambda_{3}$ that appears in the bank's loss function. Finally, concern about nominal interest rate fluctuations is captured by the term associated with $\lambda_{4}$ similar to Woodford (2003a).

\subsection{Optimal Taylor rule for an open economy}

We assume that the central bank's behavior can be empirically understood to be the result of a monetary policy that arises from minimizing (10) with respect to $(\pi, x, i, e)$ subject to $(2),(3),(4)$, and (7). However, this problem can be solved in a simple fashion if (7) is first replaced in Equation (10) which generates the following loss function:

$$
\begin{aligned}
\frac{\mathcal{L}_{t}}{2}= & \left(\pi_{t}-\bar{\pi}\right)^{2}+\lambda_{1} x_{t}^{2}+\lambda_{2}\left(e_{t}-e^{n}\right)^{2} \\
& +\lambda_{3}\left(\left(i_{t-1}-i_{t-1}^{*}\right)-\left(\pi_{t}-\pi_{t}^{*}\right)-\varphi_{t-1}\right)^{2}+\lambda_{4}\left(i_{t}-i_{t-1}\right)^{2}
\end{aligned}
$$

Then, Equation (4) is replaced in Equation (2) and therefore the optimal monetary policy arises from minimizing Equation (11) with respect to $(\pi, x, i, e)$ subject to (2) and (3). The corresponding Lagrangian function associated with this problem is then

$$
\begin{aligned}
\mathcal{L}=E_{t} & \left\{\sum _ { t = 0 } ^ { \infty } \beta ^ { t } \left\{\frac{L_{t}}{2}+\phi_{1}\left[x_{t}-x_{t+1}-\delta x_{t-1}+\sigma\left(i_{t}-\pi_{t+1}-r^{n}\right)-\alpha_{1} e_{t}-\gamma^{*} x_{t}^{*}-\varepsilon_{1 t}\right]\right.\right. \\
& \left.\left.+\phi_{2}\left[\pi_{t}-\beta \pi_{t+1}-\gamma \pi_{t-1}-k x_{t}-\alpha_{2} e_{t}-\varepsilon_{2 t}\right]\right\}\right\}
\end{aligned}
$$

where $\beta \in(0,1)$ is the discount rate, $\phi_{1}$ and $\phi_{2}$ are the Lagrange multipliers, and it is assumed that they are constant in the regime implemented by 
the central bank. ${ }^{18}$ Because the loss function is a quadratic function the following first-order conditions, which are necessary and sufficient, solve the optimization problem. ${ }^{19}$ Solving the first-order equations jointly with (2) and (3), the endogenous variables $\phi_{1}$ and $\phi_{2}$ can be eliminated and everything can be collapsed into the following reduced form equation:

$$
\begin{aligned}
i_{t}= & \beta_{0}+\beta_{1} E_{t} x_{t+1}+\beta_{2} x_{t}+\beta_{3} x_{t-1}+\beta_{4} x_{t}^{*}+\gamma_{1} \pi_{t}+\gamma_{2} \pi_{t-1}+\gamma_{3} \pi_{t}^{*} \\
& +\delta_{1} E_{t} i_{t+1}+\delta_{2} i_{t-1}+\delta_{3} i_{t-1}^{*}+\delta_{4} \varphi_{t-1}+\frac{\varepsilon_{1 t}}{\sigma \Gamma}-\frac{\varepsilon_{2 t}}{\beta \Gamma}
\end{aligned}
$$

where the parameter vector $\theta=\left(\beta_{0}, \beta_{1}, \beta_{2}, \beta_{3}, \beta_{4}, \gamma_{1}, \gamma_{2}, \gamma_{3}, \delta_{1}, \delta_{2}, \delta_{3}, \delta_{4}\right)$ consists of reduced form parameters that are functions of the deep structural parameters of the model as derived formally in Appendix A and the parameter $\Gamma$ is defined as

$$
\Gamma \equiv\left[1+\left(\frac{\alpha_{1} m_{1}+\alpha_{2} m_{2}}{\sigma m_{1} \lambda_{2}}\right)\left(\frac{\alpha_{1}}{\sigma}-\frac{\alpha_{2}}{\beta}\right) \lambda_{4}(1+\beta)\right]
$$

where constants $m_{1}$ and $m_{2}$ are defined in Appendix A.

We call the optimal monetary rule of Equation (12) the optimal Taylor rule for an open economy. It is important to note that exchange rates (real or nominal) do not directly appear in the optimal Taylor rule. This is interesting precisely because it could be considered that the optimal monetary rule for an open economy would involve the reaction of nominal interest rate to changes in the real exchange rate, since it has been explicitly assumed that real exchange rate fluctuations are present in the central bank's loss function (Equation (10)) under $\lambda_{3}>0$. However, the exchange rate does not appear because of the assumption of interest rate parity equation (7) between the domestic economy and its trading partner, which implies that movements in the domestic economy's real exchange rate are due to exogenous factors such as the inflation rate, interest rate, and risk premium relative to the trading partner.

18. The constancy of these Lagrange multipliers is a restriction that Woodford (2003b), for example, does not impose. However, we do this to maintain an analysis with an explicit solution; otherwise we would have to resort to numerical simulations. This constancy means that the central bank would have constant reactions over time to changes in (2) and (3).

19. See Appendix A for an explicit solution to this optimization problem. 


\section{a. Analysis of the optimal Taylor rule}

\section{Closed economy and the original Taylor rule}

It is instructive to briefly analyze the sufficient conditions under which the monetary rule of Equation (12) becomes a Taylor rule for a closed economy similar to that considered by Taylor (1993) for the United States economy. A closed economy satisfies $\delta^{*}=\alpha_{1}=\alpha_{2}=0$ which implies $\Gamma \equiv 1$. In addition, under naive expectations $\mathrm{E}_{t} x_{t+1}=x_{t}$ and without inflationary inertia in the Phillips curve, $\gamma=0$, the structural equation that gives rise to Equation (12) becomes:

$$
i_{t}=r^{n}+\left(\frac{\delta}{\sigma}-\frac{k}{\beta}\right) x_{t}+\frac{1}{\beta} \pi_{t}+\frac{\varepsilon_{1 t}}{\sigma}-\frac{\varepsilon_{2 t}}{\beta}
$$

Taylor (1993) proposes characterizing the monetary policy of the United States in the 1970s and 1980s as based on a rule such as that given in Equation (13) with a coefficient associated with gap $x$ of around 0.5 and a coefficient associated with the inflation rate $\pi$ around 1.5. Furthermore, as outlined above, Taylor's work generated what Woodford (2003) has called the Taylor principle, which means that the coefficient associated with $\pi$ is strictly greater than one. The Taylor princple implies that the nominal interest rate varies more than proportionally to the variation in inflation in period $t$. Note that in the optimal rule in a closed economy the coefficient associated with $\pi$ is $1 / \beta$ so it is necessarily greater than one because $\beta \in(0,1)$. Therefore, the case of the Taylor rule for a closed economy satisfies the Taylor principle. In fact, the values 0.5 and 1.5 that Taylor proposes can be replicated in this model under the parametric structural assumption $\beta=2 / 3, \sigma=1, k=1 / 6, \delta=3 / 4$.

In addition, it should be emphasized that if the inflation rate presents a certain inertia in the sense of the structural parameter such that $\gamma \in(-1,1)$ then the optimal reaction of monetary policy in the long run, compatible with a steady $\operatorname{state}^{20}$, is 


$$
\frac{d i_{e}}{d \pi_{e}} \equiv L R_{\pi}=\frac{1-\gamma}{\beta}
$$

where $\pi_{t}=\pi_{e}$ and $i_{t}=i_{e}$ for all $t$ in the steady state. A sufficient condition to satisfy the Taylor principle in this case is then $1>\beta+\gamma$. In addition, the coefficient associated with the gap $x$ is not necessarily positive in Equation (13) since it is possible that $(\delta / \sigma)-(k / \beta)<0$, although empirically it does not appear to be a relevant case. Finally, demand shocks (changes in $\varepsilon_{1}$ ) and supply shocks (changes in $\varepsilon_{2}$ ) optimally increase and decrease, respectively, the interest rate $i_{t}$.

\section{Open economy}

We now study the structural optimal Taylor rule for an open economy $\left(\alpha_{1} \neq 0\right.$ and $\alpha_{2} \neq 0$ ) deduced in the appendix in Equation (A13) which is the equation that gives rise to the reduced optimal Taylor rule given by Equation (12). The signs of the different coefficients in Equation (A13) are generally ambiguous because they depend specifically on whether the term $\left(\alpha_{1} / \sigma\right)-\left(\alpha_{2} / \beta\right)$ is positive or negative. To simplify the analysis, we make an assumption on some parameters:

$$
\sigma k=1-\beta(1-\beta \delta)>0 .
$$

Under this restritcion we obtain $\left(\left(\alpha_{1} m_{1}+\alpha_{2} m_{2}\right) / \alpha m_{1}\right)=\left(\left(\alpha_{1} / \sigma\right)-\left(\alpha_{2} / \beta\right)\right)$ where the definitions of $m_{1}$ and $m_{2}$ given in equations (A6) and (A9) of the appendix were used. Hence, the constant $\Gamma$ can be simplified:

$$
\Gamma \equiv 1+\left(\frac{\alpha_{1}}{\sigma}-\frac{\alpha_{2}}{\beta}\right)^{2}\left(\frac{\lambda_{4}(1+\beta)}{\lambda_{2}}\right)
$$

We can conclude, therefore, that $\Gamma \geq 1$ given that $\lambda_{4}(1+\beta) / \lambda_{2}>0$. Equation (A13) is simplified somewhat, generating the following equation: 


$$
\begin{aligned}
& i_{t}=\frac{1}{\Gamma}\left[r^{n}+\left(\frac{\alpha_{1}}{\sigma}-\frac{\alpha_{2}}{\beta}\right) e^{n}\right]+\frac{E_{t} x_{t+1}}{\sigma \Gamma}+\frac{1}{\Gamma}\left\{\left(\frac{\alpha_{1}}{\sigma}-\frac{\alpha_{2}}{\beta}\right)\left(\frac{\alpha_{2} \lambda_{1}}{k \lambda_{2}}\right)-\left(\frac{1+\beta^{2} \delta}{\beta \sigma}\right)\right\} x_{t} \\
& +\frac{\delta}{\sigma \Gamma} x_{t-1}+\left(\frac{1}{\beta \Gamma}+\left(\frac{\lambda_{3 \beta}\left(1+\frac{1}{1-\beta \gamma}\right)}{\lambda_{2} \Gamma}\right)\left(\frac{\alpha_{1}}{\sigma}-\frac{\alpha_{2}}{\beta}\right)^{2}\right) \pi_{t}-\frac{\gamma}{\beta \Gamma} \pi_{t-1} \\
& +\frac{\delta^{*}}{\sigma \Gamma} x_{t}^{*}+\frac{\delta^{*}}{\sigma \Gamma} x_{t}^{*}-\left(\frac{\lambda_{3 \beta}\left(1+\frac{1}{1-\beta \gamma}\right)}{\lambda_{2} \Gamma}\right)\left(\frac{\alpha_{1}}{\sigma}-\frac{\alpha_{2}}{\beta}\right)^{2} \pi_{t}^{*} \\
& +\left(\frac{\lambda_{3}\left(\beta+\sigma m_{1}\right)}{\Gamma}\right)\left(\frac{\alpha_{1}}{\sigma}-\frac{\alpha_{2}}{\beta}\right)^{2} i_{t-1}^{*} \\
& +\left(\frac{\lambda_{3 \beta}\left(1+\frac{1}{1-\beta \gamma}\right)}{\lambda_{2} \Gamma}\right)\left(\frac{\alpha_{1}}{\sigma}-\frac{\alpha_{2}}{\beta}\right)^{2} \varphi_{t-1}+\frac{\beta \lambda_{4}}{\Gamma}\left(\frac{\alpha_{1}}{\sigma}-\frac{\alpha_{2}}{\beta}\right)^{2} E_{t} i_{t+1} \\
& +\left(\frac{\lambda_{4}-\lambda_{3} \beta\left(1+\frac{1}{1-\beta \gamma}\right)}{\lambda_{2} \Gamma}\right)\left(\frac{\alpha_{1}}{\sigma}-\frac{\alpha_{2}}{\beta}\right)^{2} i_{t-1}+\frac{\varepsilon_{1 t}}{\sigma \Gamma}-\frac{\varepsilon_{2 t}}{\beta \Gamma}
\end{aligned}
$$

Then, as the optimal Taylor rule has interest rate lags and leads, it is important to be careful when determining whether the Taylor principle is satisfied in the long term. We must find in steady state the long-term effect of a 1\% change in $\pi$ over $i$ according to the optimal Taylor rule. We replace $\pi_{t}=\pi_{e}$ and $i_{t}=i_{e}$ for all $t$, where the subscript $e$ means evaluated in steady state, and then we obtain $\left(d i_{e} / d \pi_{e}\right) \equiv L R_{\pi}$ which yields:

$$
L R_{\pi}=\frac{\frac{1-\gamma}{\beta \Gamma}+\left(\frac{\lambda_{3} \beta\left(1+\frac{1}{1-\beta \gamma}\right)}{\lambda_{2} \Gamma}\right)\left(\frac{\alpha_{1}}{\sigma}-\frac{\alpha_{2}}{\beta}\right)^{2}}{1-\left[\frac{(1+\beta) \lambda_{4}-\lambda_{3} \beta\left(1+\frac{1}{1-\beta \gamma}\right)}{\lambda_{2} \Gamma}\right]\left(\frac{\alpha_{1}}{\sigma}-\frac{\alpha_{2}}{\beta}\right)^{2}}
$$


The following result gives the sufficient conditions for satisfying $L R_{\pi}>1$ which is the long-term version of the Taylor principle (compatible with a steady state) for an open economy.

Proposition 1. If $\sigma k=1-\beta(1-\beta \delta)$ and $1>\beta+\gamma$ then the optimal Taylor rule for an open economy given by (14) satisfies $L R_{\pi}>1$.

Proof: First, note that $L R_{\pi}>0$ is satisfied if the denominator is positive, given that the numerator is always positive. Therefore, the following must be satisfied:

$1>\left[\frac{(1+\beta) \lambda_{4}-\lambda_{3} \beta\left(1+\frac{1}{1-\beta \gamma}\right)}{\lambda_{2} \Gamma}\right]\left(\frac{\alpha_{1}}{\sigma}-\frac{\alpha_{2}}{\beta}\right)^{2}$

which is an inequality that is simplified if

$\Gamma \equiv 1+\left(\frac{\alpha_{1}}{\sigma}-\frac{\alpha_{2}}{\beta}\right)^{2}\left(\frac{\lambda_{4}(1+\beta)}{\lambda_{2}}\right)$

is replaced and then the equation is reorganized to be expressed as

$1+\left[\frac{\lambda_{3} \beta\left(1+\frac{1}{1-\beta \gamma}\right)}{\lambda_{2} \Gamma}\right]\left(\frac{\alpha_{1}}{\sigma}-\frac{\alpha_{2}}{\beta}\right)^{2}$

Clearly this condition is always positive given that $1>\beta \gamma$ and that the other terms are positive. In addition, note that $L R_{\pi}>1$ is satisfied once the constant $\Gamma$ is replaced and it is noted that $1>\beta+\gamma$ is satisfied by assumption.

Corollary. The condition $1>\beta+\gamma$ implies that it is more likely that the central bank of a small open economy that implements an optimal Taylor rule does not satisfy the Taylor principle the greater the persistence $\gamma>0$ in the inflation rate, for a given intertemporal discount rate of the domestic economy. This shows that an inflation 
rate that is highly persistent, say has a unit root or a stochastic trend, should not satisfy the Taylor principle. This key observation will be crucial for our empirical results.

Now, the coefficients associated with $x_{t+1}$ and $x_{t-1}$ in Equation (14) are positive, while the sign associated with $x_{t}$ has an ambiguous sign even under the simplifying assumption $\sigma k=1-\beta(1-\beta \delta)$. The long-term effect is also ambiguous. To see this, note that we replaced $x_{t}=x_{e}$ and $i_{t}=i_{e}$ for all t, and then we obtain $\left(d i_{e} / d x_{e}\right) \equiv L R_{x}$ :

$$
L R_{x}=\frac{\frac{1}{\Gamma}\left\{\left(\frac{\alpha_{1}}{\sigma}-\frac{\alpha_{2}}{\beta}\right)\left(\frac{\alpha_{2} \lambda_{1}}{k \lambda_{2}}\right)-\left(\frac{1+\beta^{2} \delta}{\beta \sigma}\right)\right\}+\frac{1+\delta}{\sigma \Gamma}}{1-\left[\frac{(1+\beta) \lambda_{4}-\lambda_{3} \beta\left(1+\frac{1}{1-\beta \gamma}\right)}{\lambda_{2} \Gamma}\right]\left(\frac{\alpha_{1}}{\sigma}-\frac{\alpha_{2}}{\beta}\right)^{2}}
$$

The denominator is positive as shown in Proposition 1, while the numerator can have either sign. Similar to the case of a closed economy, the optimal reaction of monetary policy to changes in the output gap can have an ambiguous sign.

Finally, it is important to note that if within the bank's loss function the weighting relative to changes in the nominal interest rate $\lambda_{4}$ is sufficiently large compared to the weighting $\lambda_{3}$ that corresponds to changes in the real exchange rate around an implicit target, the optimal Taylor rule smooths the movement of the nominal interest rate. This is summarized in the following proposition.

Proposition 2. If $\sigma k=1-\beta(1-\beta \delta),\left(\alpha_{1} / \sigma\right) \neq\left(\alpha_{2} / \beta\right)$ and $\left(\lambda_{4} / \lambda_{3}\right)$ $\geq \beta(1+(1 /(1-\beta \gamma)))$ are satisfied, then the optimal Taylor rule in Equation (14) smooths the temporal behavior of the nominal interest rate.

Proof: Note that in Equation (14) the coefficient associated with $E_{t} i_{t+1}$ is always positive under the assumption $\left(\alpha_{1} / \sigma\right) \neq\left(\alpha_{2} / \beta\right)$. In addition, the associated coefficient $i_{t-1}$ is positive under $\left(\alpha_{1} / \sigma\right) \neq\left(\alpha_{2} / \beta\right)$ and $\left(\lambda_{4} / \lambda_{3}\right) \geq \beta(1+(1 /(1-\beta \gamma)))$. Thus, we conclude that under the conditions formulated, a central bank in a small open economy finds it optimal to smooth out changes in the interest rate. 
Woodford (2003a) has argued that optimal monetary rules can have a smoothing effect on the nominal interest rate even in closed economies where the real exchange rate does not play a role. It is important to note that in our model we obtain an optimal monetary rule with smoothing of the nominal interest rate only if the economy is open, i.e., $\alpha_{1}>0$ and $\alpha_{2}>0$ such that $\alpha_{1} \neq \alpha_{2}$ under the assumption $\sigma k=1-\beta(1-\beta \delta)$. As can be observed in Equation (14) if $\alpha_{1}=\alpha_{2}=0$ we end up with a rule that does not smooth out the behavior of the nominal interest rate. Naturally, we are not arguing that a closed economy model cannot present smoothing in the behavior of the nominal interest rate. In fact, Woodford (2003a) has argued that smoothing of the behavior of the nominal interest rate can be present in an optimal monetary policy even if the central bank's loss function does not take into account changes in the nominal interest rate. What we note here, however, is that smoothing of nominal interest rate behavior occurs in our model only for an open economy.

The following proposition gives sufficient conditions for the optimal Taylor rule to be consistent with a dynamic system with a unique steady state.

Proposition 3. If $\sigma k=1-\beta(1-\beta \delta), 1>\beta+\gamma, \gamma \in(-1,1)$, $0>\alpha_{1} \beta^{2} \gamma>\alpha_{2} \sigma, \lambda_{2} \leq \beta \lambda_{3}^{2}$ and

$$
\lambda_{1}<\min \left\{\frac{k^{2}\left[\lambda_{3}(2-\beta \gamma)\right]+1}{\beta \gamma(1-\beta-\gamma)}, \frac{k(1-\beta \delta)(1-\beta)\left(\lambda_{3}(2-\beta \gamma)+1\right)}{(1-\gamma) \sigma \beta \gamma}\right\},
$$

then the optimal Taylor rule for Equation (14) is consistent with a dynamic system that has a unique steady state.

See Appendix A for the proof of this proposition. It is important to note that we do not study the conditions for the local or global dynamic properties of the steady state of the underlying linear dynamic system. We assume, in fact, that the dynamic around the steady state is not divergent: It can be local or globally convergent or even a saddle point. The conditions for it to be convergent or a saddle point with a trajectory that goes to steady state is outside the scope of this article, due to the complexity of carrying out this analytical exercise, given the dimensions of the dynamic system that would require analysis. What is important is that we are assuming that there is a dynamic trajectory that goes to 
the steady state in the long run and that the economy ends up there, through implementation of the optimal Taylor rule. Also, since our concern is more empirical than theoretical in analyzing the behavior of the Bank of the Republic in the case of Colombia we do not go further in studying the theoretical model.

\section{ESTIMABLE EMPIRICAL SPECIFICATION}

The econometric estimation of the reduced form Equation (12) is carried out using a Markov-switching model that considers the existence of different states or regimes. It should be pointed out that the change from one regime to another is characterized by a dichotomous stochastic variable $\left(\mathrm{S}_{t}\right)$ that is endogenous to the system and which represents the state or regime of the economy where $\mathrm{S}_{t} \in\{1,1\}$. Therefore, from Equation (12) the econometric model can be written as:

$$
\begin{aligned}
i_{t}= & \beta_{0}+\beta_{1} E_{t} x_{t+1}+\beta_{2} x_{t}+\beta_{3} x_{t-1}+\beta_{4} x_{t}^{*} \\
& +\gamma_{1} \pi_{t}+\gamma_{2} \pi_{t-1}+\gamma_{3} \pi_{t}^{*} \\
& +\delta_{1} E_{t} i_{t+1}+\delta_{2} i_{t-1}+\delta_{3} i_{t-1}^{*}+\delta_{4} \varphi_{t-1}+u_{t}
\end{aligned}
$$

where $\left(\varepsilon_{1 t} / \sigma \Gamma\right)-\left(\varepsilon_{2 t} / \beta \Gamma\right) \equiv u_{t} \sim \operatorname{iid}\left(0, \sigma_{\mathrm{S}_{t}}^{2}\right)$ is an error or disturbance and where we define $\beta_{\mathrm{S}_{t}}=\beta_{0}\left(1-\mathrm{S}_{t}\right)+\beta_{1} \mathrm{~S}_{t}, \sigma_{\mathrm{S}_{t}}^{2}=\sigma_{0}^{2}\left(1-\mathrm{S}_{t}\right)+\sigma_{1}^{2} \mathrm{~S}_{t}$. The nature of the system is that the variable $\mathrm{S}_{t}$ has the property of a first-order Markov process, that is, the regime at the time is determined only by the preceding regime and the evolution of regime changes is associated with the realization of that stochastic process. The probabilities of transition between the two states represent this Markovian property:

$$
\begin{aligned}
& \operatorname{Pr}\left[\mathrm{S}_{t}=0 \mid \mathrm{S}_{t-1}=0\right]=\mathrm{p}, \operatorname{Pr}\left[\mathrm{S}_{t}=1 \mid \mathrm{S}_{t-1}=1\right]=\mathrm{q}, \\
& \operatorname{Pr}\left[\mathrm{S}_{t}=1 \mid \mathrm{S}_{t-1}=0\right]=1-\mathrm{p}, \operatorname{Pr}\left[\mathrm{S}_{t}=0 \mid \mathrm{S}_{t-1}=1\right]=1-\mathrm{q}
\end{aligned}
$$

where $\mathrm{p}$ is the probability of the economy being in state 0 at time $t$ given that it was in that same state at time $t-1$; q is the probability of the economy being in state 1 at time $t$ given that it was in that same state in the preceding time period; and $1-\mathrm{p}$ and $1-\mathrm{q}$ are the probabilities of transition from one regime to the other. 


\section{DATA For Colombia}

The frequency of the Colombian data is quarterly and the data covers the first quarter of 1990 through the fourth quarter of 2011. The data used to estimate the econometric model are succinctly described as follows:

- Intervention interest rate: for Colombia, we take the datum of the interbank interest rate of the Bank of the Republic ${ }^{21}, i_{t}$. The intervention rate of the United States, $i_{t}^{*}$, is taken from the Federal Reserve (FED).

- Output gap: defined as the difference in the logarithm of observed and potential output. The datum for Colombia is provided by the Bank of the Republic, $x_{t}$, and that of the United States is the result of applying the Hodrick-Prescott filter to its real observed GDP, which is taken from the Bureau of Economic Analysis (BEA) of the United States, $x_{t}^{*}$.

- Inflation rate: the Colombian data are from the National Statistics Department and Bank of the Republic, $\pi_{t}$. Data from the BEA are used for United States inflation $\pi_{t}^{*}$.

- Risk premium: This is from the Chicago Board Options Exchange Market Volatility Index, $\varphi_{t}$.

\section{Results}

\subsection{Estimation of the modified Taylor rule under Markov switching 22}

Table 1 reports the results of the estimation of the reduced-form model of the optimal Taylor rule for an open economy (12) using a Markovswitching methodology with Colombian quarterly data for the period 1990-I to 2011-IV. Statistical tests were performed to determine the existence of two or more regimes, however the evidence suggests that in the period studied there are just two monetary policy regimes in terms of the estimated Taylor rule.

21. The interbank interest rate is used because it is strongly influenced by the Bank of the Republic's intervention rate. As the institution itself acknowledges, "The rate is more heavily influenced by policies of the monetary authority, as the contraction and expansion operations are concentrated in the same periods, between 1 and 14 days" (Bank of the Republic, 1999, p. 16).

22. The empirical model follows the theoretical development of Hamilton (1994) and Krolzig (1997). See details in Appendix B. 
Table 1 shows the empirical results for the two regimes obtained, where the confidence interval is reported for the parameter of the variable with bootstrapped standard errors and the $t$ statistic under standard errors from maximum likelihood. As the table shows, the conclusions are similar under both estimation methods, where the exceptions are for the forward interest rate $i_{t+1}$ in regime 0 , which is statistically significant under standard errors of the maximum likelihood procedure but not statistically significant under bootstrapped standard errors. The other exception is for the output gap variable with a one-period lag, $x_{t-1}$ and the current output gap $x_{t}$ for regime 1 , which are statistically significant under maximum likelihood standard errors but are not statistically significant under bootstrapped standard errors. We prefer the statistical inference under the bootstrap procedure which is a more conservative approach.

Regime 0 coincides with the period during which the BR behaves under inflaton targeting (IT) while regime 1 coincides with the period in which the political constitution granted the central bank technical independence from the government, and the BR conducted monetary policy under a structure that was not specifically inflation targeting, as defined in the literature, but which nonetheless had similar characteristics, such as the public announcement of a quantitative inflation target. In this paper, this is referred to as a regime with no inflation targeting (NIT).

To understand why we denote regimes 0 and 1 this way, consider Figure 1 , which reports the filtered probabilities or occurrence probabilities of regime 0 (IT) on the vertical axis with the quarters on the horizontal

\section{Figure 1. IT regime 0 occurrence probabilities}

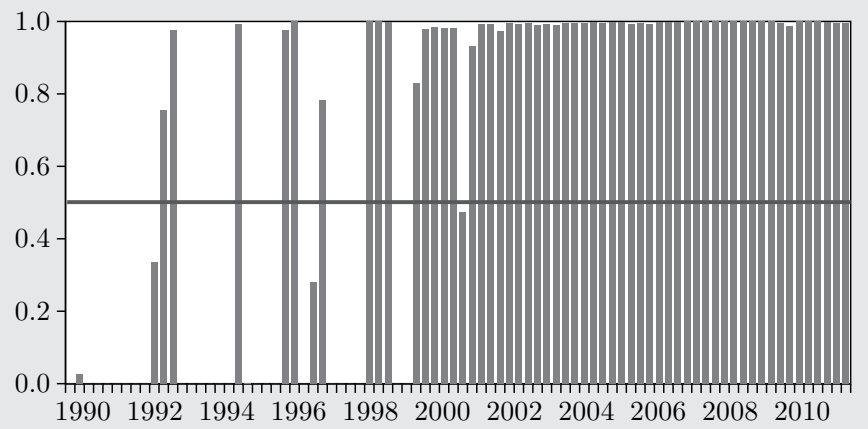




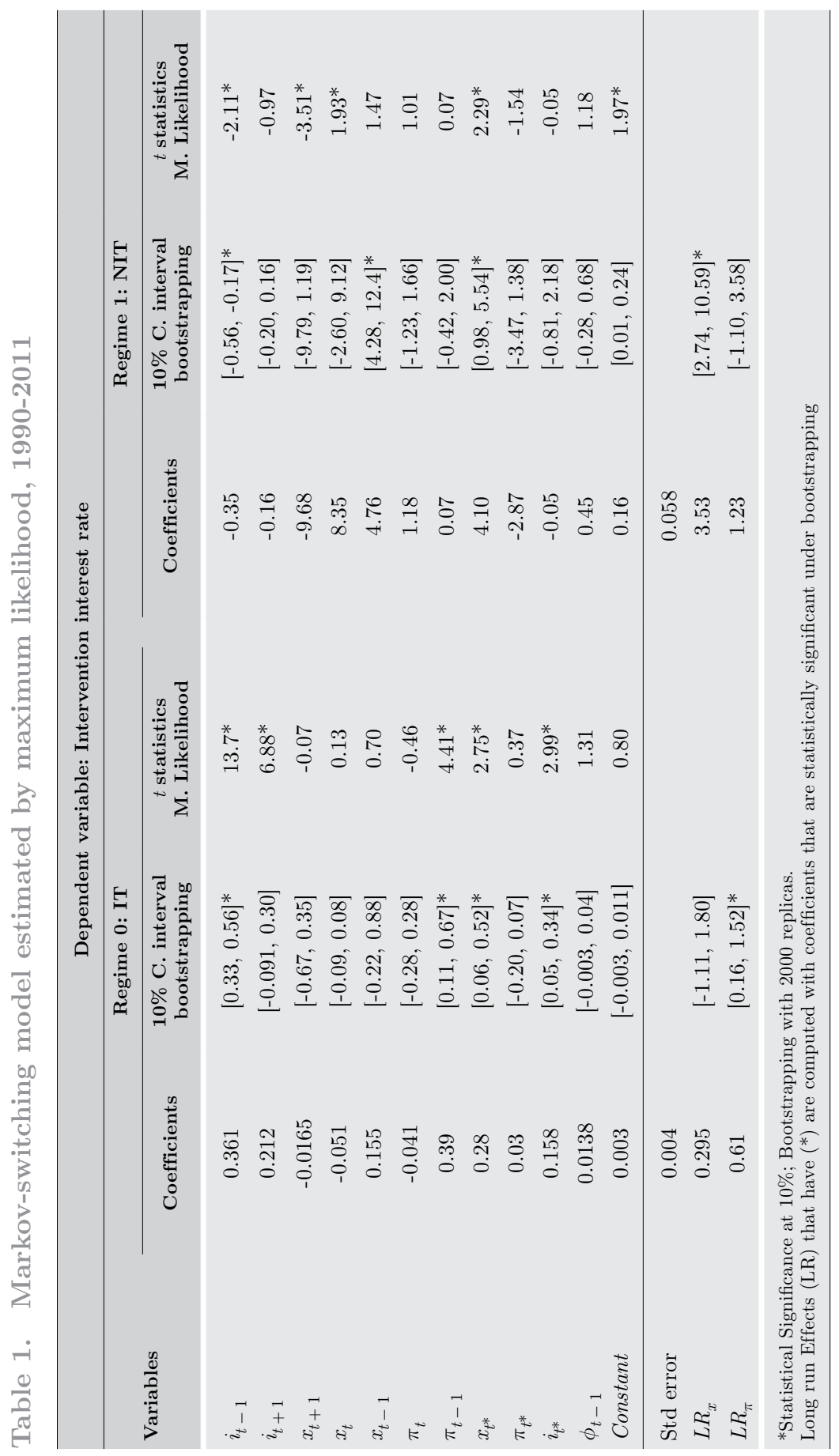


axis between 1990 and 2011. If the probability bar in the figure is greater than 0.5 it means that in that quarter, regime 0 is operating, while if the bar is less than 0.5 , it means that in that quarter regime 1 is operating. As shown in the figure, after October 2000, when the Bank of the Republic announces its target inflation rate strategy, regime 0 predominantly obtains probabilities greater than 0.5 , which explains why we call this the inflation targeting regime (IT). In contrast, prior to October 2000, regime 1 predominantly obtains probabilities greater than 0.5 , and is thus referred to as the regime with no inflation targeting (NIT).

Returning to Table 1, it indicates that in regime 0 (IT) the Bank's behavior smooths movements of the intervention rate because the variable $i_{t-1}$ is statistically significant and positive. This does not occur in regime 1 (NIT), which shows behavior not aimed at smoothing changes in the intervention rate in the period prior to October 2000. With respect to the relationship of the intervention interest rate to Colombia's output gap, what is observed is that the coefficients associated with the current level $\left(x_{t}\right)$ have opposing signs in regime 0 and 1 while they have the same sign in both regimes for the forward gap $\left(x_{t+1}\right)$ and lagged gap $\left(x_{t-1}\right)$ variables. In addition, the values in absolute terms differ substantially in the two regimes. However, only in regime 1 is the intervention interest rate significant and statistically related to the output gap variables. This suggests that the BR followed a monetary policy prior to October 2000 that reacted strongly to changes in the output gap, especially with respect to the output gap lagged by one period according to bootstrapping standard errors. Using only the statistically significant variables according to bootstrapping standard errors, for regime 1 we can compute the long-term effect (LR) on the intervention interest rate, compatible with a steady state, of a one percentage-point change in the ouput gap in period $t$.

$$
L R_{x}^{1}=\frac{4.76}{1+0.35}=3.53
$$

This marginal effect is statistically significant because zero is not in the confidence interval at $90 \%$ with bootstrapping standard errors, which is $[2.74,10.59]^{*}$. In practical terms, this long-term effect is significant because for each one-point increase in the output gap, the BR in regime 1 (NIT) increases the interest rate by 3.5 percentage points 
on average. In addition, using the statistically significant variables in regime 0 we find that $L R_{x}^{0}=0.29$, within the confidence interval at $90 \%$ with bootstrapping standard errors, which is in $[-1.11,1.80]$. This means that the null hypothesis that the BR in regime 0 (IT) did not react to changes in the output gap cannot be rejected.

With respect to the inflation rate, we find that the signs of the point estimates of the parameters associated with the current inflation rate $\left(\pi_{t}\right)$ variable in the two regimes are also different, while the signs of the lagged inflation rate $\left(\pi_{t-1}\right)$ coincide. As observed with the output gap, the actual absolute values of the inflation rate also vary from one regime to another. Only in regime 0 (IT) do we find that lagged inflation is statistically significant while in regime 1 (NIT) none of the inflation variables are statistically significant. This suggests that the $\mathrm{BR}$ only reacted statistically to changes in the inflation rate in regime 0 under inflation targeting. Again, using only the statistically significant variables according to bootstrapping standard errors, for regime 0 we can compute the long term (LR) effect on the intervention interest rate, compatible with a steady state, of a one percentage-point change in period $t$ of inflation:

$$
L R_{\pi}^{0}=\frac{0.39}{1-0.36}=0.61
$$

This estimate is in the $90 \%$ confidence interval with bootstrapping standard errors $[0.16,1.52]^{*}$ indicating that at the $10 \%$ significance level, the null hypothesis under IT that the BR did not affect the intervention interest rate in the face of changes in the average interest rate in the long term can be rejected. Moreover, at the $10 \%$ significance level the null hypothesis that the Bank has a $L R_{\pi}^{0}>1$, as the Taylor principle suggests, cannot be rejected. In particular, note that values greater than 1, up to 1.52, are within this confidence interval, providing evidence that in regime 0 with IT the BR satisfies the Taylor principle. In addition, the long-term effect for regime 1 is $L R_{\pi}^{1}=1.23$ with a confidence interval of $90 \%$ with bootstrapping standard errors $[-1.10,3.58]$. Although the specific value is greater than 1 , the confidence interval shows that the null hypothesis that $L R_{\pi}^{1}=0$ cannot be rejected at $10 \%$, indicating that the $\mathrm{BR}$ in the regime without inflation targeting did not react to changes in the inflation rate on average, and therefore, it probably did not satisfy the Taylor principle in that regime. 
The empirical results found regarding the output gap and the inflation rate suggest that the Bank of the Republic in Colombia fundamentally changed its monetary policy in October 2000 by adopting an inflation targeting monetary strategy, as we find that in regime 1 (NIT) the $\mathrm{BR}$ did not react to changes in the inflation rate, while in regime 0 (IT) it reacted in a way that is compatible with Taylor's principle. In addition, while in regime 1 (NIT) the BR reacted strongly to changes in the output gap, in regime 0 (IT) we find that it did not react to changes in this variable.

Table 1 shows that in both regimes the Bank of the Republic reacted in a positive and statistically significant way, at a $10 \%$ significance level, with respect to the United States output gap $\left(x_{t}^{*}\right)$, and this reaction was 20 times stronger in regime 1 than in regime 0 (4.1 versus $0.28)$. This is most likely because there is an exchange rate band in this period that the BR defended for several years. Moreover, only in regime 0 did the $\mathrm{BR}$ seem to have reacted in a positive and statistically significant way, at a $10 \%$ significance level, to changes in the lagged intervention rate $\left(i_{t-1}{ }^{*}\right)$ of the United States, while it did not react on average to the U.S. inflation rate $\left(\pi_{t}^{*}\right)$.

As can be seen in Table 2, in probabilistic terms, both regimes are relatively persistent over time in the period studied, since the probability of remaining in regime 0 is 0.92 while for regime 1 it is 0.84 , indicating incidentally that regime 0 (IT) is more persistent than regime 1 (NIT) in the period studied.

\section{Table 2. Transition matrix}

\begin{tabular}{lcc}
\hline & Regime 0 & Regime 1 \\
Regime 0 & 0.912 & 0.088 \\
Regime 1 & 0.162 & 0.838 \\
\hline
\end{tabular}

Given the estimated probabilities of transition, the average length in each state can be calculated using the following equations:

$$
\sum_{i=1}^{\infty} i q^{i-1}(1-q)
$$




$$
\sum_{i=1}^{\infty} i p^{i-1}(1-p)
$$

Table 3 indicates that the average duration of the IT regime is 55.3 quarters, while the average duration of the NIT regime is 6.17.

Table 3. Duration of regimes

\begin{tabular}{lcc}
\hline & Regime 0 & Regime 1 \\
\hline Regime 0 & 55.3 & 12.47 \\
Regime 1 & 31.7 & 6.17 \\
\hline
\end{tabular}

\subsection{Taylor's principle and persistent inflation rate behavior}

As described in the previous section, the BR changed its monetary policy by implementing an inflation targeting strategy after October 2000 in Colombia. This change reveals that the intervention interest rate reacted prevalently to changes in the output gap in regime 1 (NIT), which coincides with the pre-inflation targeting period, while it did not react to the output gap in regime 0 , which coincides with the inflation targeting period. In addition, when the BR implemented the target inflation rate strategy in October 2000, it generated a monetary policy that reacted strongly to changes in inflation and is compatible with the Taylor principle, something that did not occur in regime 1. Ideally, in order to conclude that the BR satisfied the Taylor principle in regime 0 (IT), the confidence interval for this regime would have been one in which the lower bound was strictly greater than 1 . However, the evidence shows that the interval at $90 \%$ confidence for $L R_{\pi}^{0}$ is $[0.16$, $1.52]^{*}$ under bootstrapping standard errors, which clearly includes values that are positive but less than 1 . Thus, while we cannot reject the hypothesis that in regime 0 the BR's inflation-targeting policy satisfies Taylor's principle, nor can we reject the possibility that it is not satisfied because we cannot reject null hypotheses where $L R_{\pi}^{0}<1$.

Our analytical results show that Taylor's principle cannot be satisfied if the inflation rate is highly persistent as a time series. Hence a unit root behavior or the inflation rate is evidence that Taylor's principle is not satisfied. 
Figure 2. Annual inflation rate in Colombia, 1990 to 2011

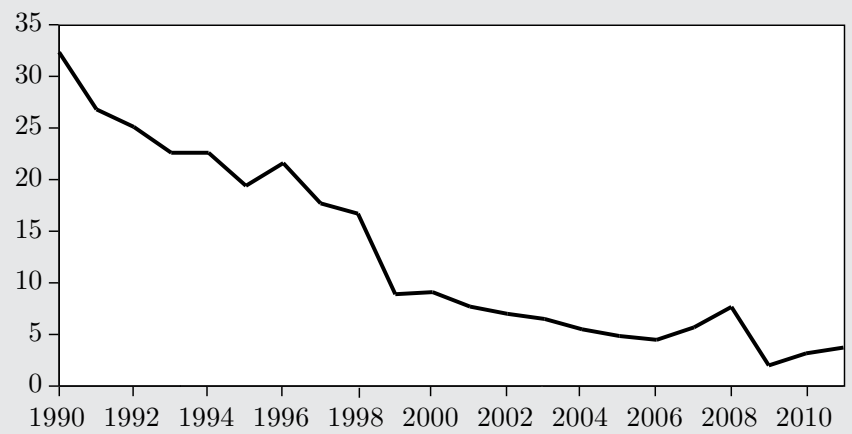

Source: Bank of the Republic of Colombia.

Moreover, as mentioned in the literature review, Murray et al. (2008) argue that the inflation rate should be a stationary time series under inflation targeting precisely because a central bank, by satisfying the Taylor principle, must react by intervening in the inflation rate more than proportionally to changes in the inflation rate, an argument consistent with our analytical results. This observation enables an indirect strategy for verifying whether the BR had implemented a monetary policy consistent with the Taylor principle after October 2000: we must verify that after October 2000 Colombia's inflation rate is a weakly stationary time series.

Figure 2 shows that Colombia's annual inflation rate appears to behave differently before and after the year 2000. Before 2000, double-digit inflation was rapidly decreasing while after 2000, according to the figure, it began to fall more slowly and remained stable at a 1-digit rate. This appears to suggest that 2000 is a year of regime switching consistent with what has been found above.

To indirectly verify the hypothesis that after 2000 the Bank of the Republic of Colombia began to satisfy the Taylor principle with a change to an IT policy, we must verify that the inflation rate should have a unit root in the regime that prevailed before October 2000 and then becomes a weakly stationary time series in the regime that prevailed after October 2000. To do this, a unit root test is implemented for a Markov-switching model following Camacho (2010), using a 
Table 4. ADF test for inflation rate under a Markov switching process

\begin{tabular}{|c|c|c|c|c|c|c|}
\hline \multicolumn{7}{|c|}{ Dependent variable: Change in inflation rate } \\
\hline \multirow[b]{2}{*}{ Variables } & \multicolumn{3}{|c|}{ Regime 0} & \multicolumn{3}{|c|}{ Regime 1} \\
\hline & Coefficient & $\begin{array}{c}\text { Std. } \\
\text { error }\end{array}$ & $t$ statistic & Coefficient & $\begin{array}{l}\text { Std. } \\
\text { error }\end{array}$ & $t$ statistic \\
\hline$\Delta \pi_{t-1}$ & 0.519 & 0.185 & 2.81 & -0.02 & 0.112 & -0.24 \\
\hline$\Delta \pi_{t-2}$ & 0.277 & 0.254 & 1.10 & -0.10 & 0.11 & -0.93 \\
\hline$\Delta \pi_{t-3}$ & 0.381 & 0.177 & 2.15 & -0.18 & 0.088 & -2.07 \\
\hline$\pi_{t-1}$ & -0.455 & 0.116 & -3.39 & 0.07 & 0.018 & 4.05 \\
\hline Trend & -0.0015 & 0.001 & -3.93 & 0.0003 & 0.0001 & 3.32 \\
\hline Constant & 0.132 & 0.0343 & 3.83 & -0.021 & 0.003 & -5.72 \\
\hline Standard error & 0.0013 & & & 0.0052 & & \\
\hline
\end{tabular}

bootstrapping procedure, based on a regime-switching augmented Dickey-Fuller regression. ${ }^{23}$

\section{Table 5. Bootstrapping DF unit root test for a Markov switching model}

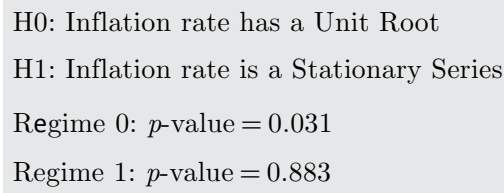

Table 4 shows the results of the estimation under maximum likelihood, while Table 5 resports the test of the hypothesis in question using standard errors under a bootstrapping procedure with 2,000 replicas, which is a more conservative procedure. According to Table 4 the coefficient associated with $\pi_{t-1}$ is the DF unit root test. As seen the $t$ stat is -3.39 for regime 0 while it is 4.05 for regime 1 . Hence, according to the Dickey-Fuller table we can reject at the $10 \%$ level that in regime 0 there is a unit root while we cannot reject at the $10 \%$ 
level that in regime 1 the inflation rate has a unit root. This same conclusion is obtained with bootstrapping standard errors as reported in Table 5 , since the $\mathrm{p}$ value of the null for regime 0 is 0.03 , which indicates that there is evidence to reject the null hypothesis of the existence of a unit root in this regime at a significance level of $10 \%$, while the $\mathrm{p}$ value for regime 1 is 0.88 , which supports the conclusion that there is no evidence to reject the null even at the $10 \%$ level that in this regime the inflation rate exhibits a unit root or stochastic trend.

In addition, the filtered probabilities or occurrence probabilities for the two regimes are estimated and shown in Figure 3. As can be observed, each of the two regimes is present in the entire period analyzed, although starting in 2000 the more prevalent regime is regime 0 , which, as shown earlier, coincides with the adoption of inflation targeting by the $\mathrm{BR}$, and in which the null hypothesis that the inflation rate has a unit root can be rejected. Likewise, regime 1 prevails before October 2000 , when the BR followed a regime of no inflation targeting, and we find that in this regime the inflation rate exhibits a unit root and therefore the Taylor principle is not satisfied.

\section{Figure 3. Regime 0 occurrence probabilities}

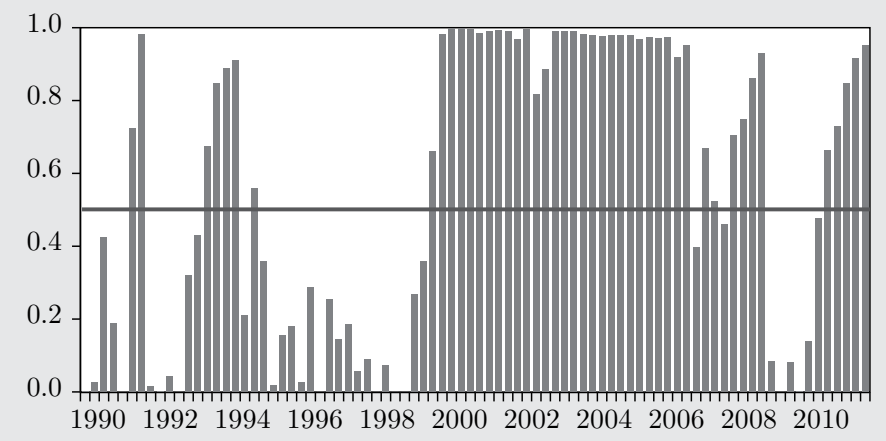

It is the prevalence of regime 0 after October of 2000 in the unit root test that gives us the confidence to argue that this is the regime closest to the IT regime identified above given that the Markov switching unit root test is independent of the previous estimation procedure. Hence, 
the evidence provides greater certainty that the regime switching in the BR's monetary policy after October 2000 satisfies the Taylor principle precisely because after implementation of the IT monetary policy the prevailing regime is compatible with the inflation rate being a stationary time series.

This result allows us to conjecture, although with great prudence, that if the BR had not adopted the IT policy in October 2000 the inflation rate would have continued to be a time series with a stochastic trend or unit root. This surely would have had repercussions for the effectiveness of the BR's monetary policy in controlling inflationary shocks, because persistent series exhibit unpredictable and sometimes volatile behavior over time. Overall, our results support the idea that an IT policy is beneficial for small open countries like Colombia because it enables central banks to control inflationary shocks by maintaining the inflation rate stable at low levels in a credible way.

\section{Concluding REMARKS}

This article has proposed and developed an optimal Taylor rule for an open economy that arises from a loss function optimization problem of a central bank that is concerned with deviations of inflation from its target, the economic cycles represented by the output gap, the desire to smooth the intervention rate and the deviation from the real exchange rate relative to a long-term goal. This optimal monetary policy is framed within a model with an intertemporal IS curve, an aggregate supply curve or Phillips curve, Fisher's equation and an interest rate parity condition, because the economy is small and open. The optimal Taylor rule has as a special case the original ad hoc Taylor rule for a closed economy as in Taylor (1993). Conditions are found under which Taylor's principle is more likely to be satisfied in the optimal Taylor rule for an open economy in which the inflation rate is not persistent over time. This shows that an inflation rate that has a unit root or a stochastic trend should not satisfy the Taylor principle.

Once the optimal Taylor's rule is obtained in its reduced form, it is estimated in a Markov-switching model for Colombia between 1990 and 2011 because the Bank of the Republic adopted an inflation targeting monetary policy midway through this period, in October 2000. We do not impose this potential structural change exogenously; rather, we allow the methodology to estimate for us the number of 
regimes in the period studied. We find two different regimes in the period studied, consistent with a change in the parameters of the optimal Taylor rule with respect to the inflation rate and the output gap, after the inflation targeting policy is adopted in October 2000. Evidence is found that in both regimes, the Bank of the Republic exhibits behavior that is diametrically opposed in terms of the way in which the intervention interest rate reacts to changes in the inflation rate and output gap. In one regime, which prevails before October 2000 and is labeled regime with no inflation targeting, the Bank of the Republic implements a monetary policy where the intervention interest rate reacts only statistically to changes in the output gap. In the other regime, which prevails after October 2000 and is labeled as a regime with inflation targeting, the intervention interest rate reacts only statistically to changes in the inflation rate. Moreover, we find that in the regime with inflation targeting, Taylor's principle can be, but is not necessarily, satisfied statistically.

Our analytical results show that an inflation rate that has a unit root or a stochastic trend should not satisfy the Taylor principle. Moreover, this analytical argument confirms the insight of Murray et al. (2008) who argue that Taylor's principle is associated with a central bank's behavior consistent with inflation that follows a stationary path over time. Hence, a unit root test is carried out for a Markov-switching model to study the relationship between Taylor's principle and the stationarity of the inflation rate. The Dickey-Fuller unit root test is carried out in a two-state Markov-switching model given the results that were obtained when the optimal Taylor rule was estimated. After October 2000, the test shows that the regime that is predominant has an inflation rate that is weakly stationary, while before October of 2000 the predominant regime has an inflation rate with unit root behavior. This additional empirical evidence provides greater certainty that the inflation targeting regime generated a policy that very likely satisfies the Taylor principle. These results support the idea that an inflation targeting policy is beneficial to small open countries like Colombia because it enables central banks to control inflationary shocks by maintaining the inflation rate at low rates in a credible way. 


\section{REFERENCES}

Ball, L. (1999a), "Efficient rules for monetary policy," International Finance 2(1): 63-83.

. (1999b), "Policy rules for open economies," in J.B. Taylor, ed., Monetary Policy Rules, NBER Studies in Business Cycles, Chicago: NBER-University of Chicago Press.

Banco de la República (1999), Informe de la Junta Directiva al Congreso de la República (Report of the Board of Directors to the Congress of the Republic), No. 2, July.

Barro, R.J. and D. Gordon, (1983), "A positive theory of monetary policy in a natural rate model," Journal of Political Economy 91(4): 589-610.

Batini, N., R. Harrison, and S.P. Millard (2003), "Monetary policy rules for an open economy," Journal of Economic Dynamics and Control 27(11/12): 2059-94.

Batini, N., P. Levine, and J. Pearlman (2009), "Monetary rules in emerging economies with financial market imperfections," in J. Galí and M. Gertler, eds., International Dimensions of Monetary Policy, National Bureau of Economic Research.

Bernal, G. and J. Tautiva (2011), "Datos en tiempo real: una aplicación a la regla de Taylor en Colombia" (Real-time data: An application of Taylor's rule in Colombia), Revista de Economía Institucional 13(24): 373-94.

Bernanke, B. and M. Gertler (2000), "Monetary policy and asset price volatility," Working Paper 7559, National Bureau of Economic Research.

. (2001), "Should central banks respond to movements in asset prices?" American Economic Review (Papers and Proceedings of the 113th Annual Meeting of the American Economic Association) 91(2): 253-257.

Camacho, M. (2010), "Markov-switching models and the unit root hypothesis in real U.S. GDP," Economics Letters 112(2): 161-64.

Carlstrom, C.T. and T.S. Fuerst (2007), "Asset prices, nominal rigidities, and monetary policy," Review of Economic Dynamics, 10(2): 256-75.

Clarida, R., J. Gali, and M. Gertler (1998), "Monetary policy rules in practice: Some international evidence," European Economic Review 42: 1033-67.

. (1999), "The science of monetary policy: A new Keynesian perspective," Journal of Economic Literature 37(4): 1661-707.

. (2000), "Monetary policy rules and macroeconomic stability: Evidence and some theory," Quarterly Journal of Economics 115(1): 147-80.

Diebold, F. X., J. Lee and G. C. Weinbach (1993), "Regime switching with timevarying transition probabilities," Working Papers 93-12, Federal Reserve Bank of Philadelphia.

Diebold, F.X., J. Lee, and G.C. Weinbach (1994). "Regime Switching with TimeVarying Transition Probabilities," in Hargreaves, Colin,P. ed., Nonstationary Time Series Analysis and Cointegration. New York and Oxford: Oxford University Press, pp. 283-302. 
Diebold, F.X., J. Lee, and G.C. Weinbach (1999), "Regime switching with timevarying transition probabilities," in F.X. Diebold and G.D. Rudebusch, eds., Business Cycles: Durations, Dynamics, and Forecasting, Princeton: Princeton University Press.

Friedman, B.M. (1990), "Targets and instruments of monetary policy," in Handbook of Monetary Economics, Vol. 2, Chapter 22: 1185-230.

Friedman, M. (1968), "The role of monetary policy," American Economic Review 58(1): $1-17$.

Giraldo, A. (2008), "Aversión a la inflación y regla de Taylor en Colombia 1994-2005" (Aversion to inflation and Taylor's rule in Colombia 1994-2005), Cuadernos de Economía (Universidad Nacional de Colombia) XXVII(49): 229-62.

Giraldo, A., M. Misas, and E. Villa (2011), "Reconstructing the recent monetary policy history of Colombia from 1990 to 2010," Ensayos sobre Politica Económica, Banco de la República. Publication pending. An initial version is available at http://www.dotec-colombia.org.

Hall, S.G., Z. Psaradakis, and M. Sola (1999), "Detecting periodically collapsing bubbles: A Markov switching unit root test," Journal of Applied Econometrics 14: $143-54$

Hamilton, J.D. (1994), Time Series Analysis, Princeton: Princeton University Press.

Krolzig, H.M. (1997), "Markov-switching vector autoregression." Lecture Notes in Economic and Mathematical Systems.

Kuzin, V. (2006), "The inflation aversion of the Bundesbank: A state space approach," Journal of Economic Dynamics and Control 30: 1671-86.

Kydland, F.E. and E.C. Prescott (1977), "Rules rather than discretion: The inconsistency of optimal plans," Journal of Political Economy 85(June):473-92.

López, M. (2004), "Efficient policy rule for inflation targeting in Colombia," Ensayos sobre Política Económica (Banco de la República) 45: 80-115.

Mishkin, F. (1999), International experiences with different monetary policy regimes," Journal of Monetary Economics 43(3): 579-605.

Murray, C., A. Nikolsko-Rzhevskyy, and D. Papell (2008), "Inflation persistence and the Taylor principle," MPRA Paper 11353, University Library of Munich, Germany.

Orphanides, A. (2000), "Activist stabilization policy and inflation: the Taylor rule in the 1970s," Finance and Economics Discussion Series 2000-13, Board of Governors of the Federal Reserve System.

Orphanides, A. (2008), "Taylor rules," in E.N. Durlauf and L.E. Blume, eds., The New Palgrave Dictionary of Economics Online. Palgrave Macmillan, 2nd Edition.

Pérez, J. (2005), "Evaluación de reglas de tasa de interés en un modelo de economía pequeña y abierta" (Evaluation of interest rate rules in a small and open model economy), Borradores de Economía (Banco de la República), 385.

Rudebusch, G. and L.E.O. Svensson (1999b), "Policy rules for inflation targeting," in J.B. Taylor, ed., Monetary Policy Rules, NBER Studies in Business Cycles, Chicago: NBER-University of Chicago Press. 
Svensson, L. (1997), Inflation forecast targeting: Implementing and monitoring inflation targets," European Economic Review 41: 1111-46.

(1999a), "Inflation targeting as a monetary policy rule," Journal of Monetary Economics 43(3): 607-54.

. (1999b), "Inflation targeting: Some extensions," Scandinavian Journal of Economics 101(3): 337-61.

. (2000), "Open-economy inflation targeting," Journal of International Economics 50(1): 155-83.

. (2008), "Inflation targeting," in E.N. Durlauf and L.E. Blume, eds., The New Palgrave Dictionary of Economics Online, 2nd Edition. Palgrave Macmillan.

. (2011), "Inflation targeting," in B.M. Friedman and M. Woodford, eds., Handbook of Monetary Economics, Elsevier B.V.

Svensson, L. and M. Woodford (2003), "Implementing optimal policy through inflation-forecast targeting," NBER Working Paper 9747, National Bureau of Economic Research.

Taylor, J.B. (1993), "Discretion versus policy rules in practice," Carnegie-Rochester Conference Series on Public Policy 39(Dec.): 195-214.

. (1999a), "A historical analysis of monetary policy rules," in Taylor, J. B., editor, Monetary Policy Rules, NBER Studies in Business Cycles Vol. 31, Chicago: NBER-University of Chicago Press.

. (1999b), Monetary Policy Rules, NBER Studies in Business Cycles Vol. 31, National Bureau of Economic Research.

. (2001), "The role of the exchange rate in monetary-policy rules," The American Economic Review 91(2): 263-7.

Walsh, C. (2003), Monetary Theory and Policy, 2nd Edition. Cambridge: MIT Press. . (2010), Monetary Theory and Policy, 3rd Edition. Cambridge: MIT Press.

Weinbach, G.C. (1993), "Regime switching with time-varying transition probabilities: Methodological issues and application to exchange rates." doctoral dissertation, University of Pennsylvania.

Woodford, M. (2001), "The Taylor rule and optimal monetary policy," American Economic Review 91(2): 232-37.

(2003a), Interest and prices: Foundations of a theory of monetary policy, Princeton: Princeton University Press.

. (2003b), "Optimal interest-rate smoothing," Review of Economic Studies 70: $861-86$. 


\section{APPENDIX A}

\section{Derivation of the optimal Taylor rule for an open} economy

Consider the following Lagrangian function:

$$
\begin{aligned}
\min _{(\pi, x, i, e)} & E_{t}\left\{\sum _ { t = 0 } ^ { \infty } \beta ^ { t } \left\{\frac{L_{t}}{2}+\phi_{1}\left[x_{t}-x_{t+1}-\delta x_{t-1}+\sigma\left(i_{t}-\pi_{t+1}-r^{n}\right)-\alpha_{1} e_{t}-\gamma^{*} x_{t}^{*}-\varepsilon_{1 t}\right]\right.\right. \\
+ & \left.\left.\phi_{2}\left[\pi_{t}-\beta \pi_{t+1}-\gamma \pi_{t-1}-k x_{t}-\alpha_{2} e_{t}-\varepsilon_{2 t}\right]\right\}\right\}
\end{aligned}
$$

which corresponds to the problem of minimizing (11) subject to $(2)$ and (3) where we assume $\phi_{j t} \equiv \phi_{j} \neq 0$ for all $t$ and $j=1,2$. The loss function is a quadratic function and the restrictions are linear, so the following first-order conditions are necessary and sufficient to resolve the optimization problem.

$$
\begin{aligned}
& \left(\pi_{t}\right): \quad-\beta^{t+1}\left[\phi_{2} \gamma\right]+\beta^{t}\left[\pi_{t}-\bar{\pi}+\varphi_{2}\right. \\
& \left.+\lambda_{3}\left(\left(i_{t-1}-i_{t-1}^{*}\right)-\left(\pi_{t}-\pi_{t}^{*}\right)-\varphi_{t-1}\right)-\beta^{t-1}\left[\sigma \phi_{1}+\phi_{2} \beta\right]\right]=0 \\
& \left(x_{t}\right): \quad-\beta^{t+1}\left[\phi_{1} \delta\right]+\beta^{t}\left[\lambda_{1} x_{t}+\phi_{1}-k \phi_{2}\right]-\beta^{t-1} \phi_{1}=0 \\
& \left(i_{t}\right): \quad \beta^{t}\left[\lambda_{4}\left(i_{t}-i_{t-1}\right)+\phi_{1} \sigma\right]+\beta^{t+1}\left[\lambda _ { 3 } \left(\left(i_{t-1}-i_{t-1}^{*}\right)\right.\right. \\
& \left.\left.\quad-\left(\pi_{t}-\pi_{t}^{*}\right)-\varphi_{t-1}\right)-\lambda_{4}\left(E_{t} i_{t+1}-i_{t}\right)\right]=0 \\
& \left(e_{t}\right): \quad \beta^{t}\left[\lambda_{2}\left(e_{t}-e^{n}\right)-\phi_{1} \alpha_{1}-\phi_{2} \alpha_{2}\right]=0
\end{aligned}
$$

From (A1) and (A2) we solve for $\phi_{2}$. We then equalize both equations to solve for $\phi_{1}$ as:

$$
\phi_{1} \equiv m_{1}\left[\left(\pi_{t}-\bar{\pi}\right)+\lambda_{3}\left(\left(i_{t-1}-i_{t-1}^{*}\right)-\left(\pi_{t}-\pi_{t}^{*}\right)-\varphi_{t-1}\right)\right]+n_{1} x_{t}
$$

where $m_{1}$ and $n_{1}$ are functions of the parameters given by 


$$
m_{1} \equiv \frac{\beta k}{\sigma k-\beta \gamma[1-\beta(1-\beta \delta)]} ; \quad n_{1} \equiv \frac{-\beta^{2} \gamma \lambda_{1}}{\sigma k-\beta \gamma[1-\beta(1-\beta \delta)]}
$$

and where we assume that the parameters satisfy

$$
\sigma k \neq \beta \gamma[1-\beta(1-\beta \delta)]
$$

Returning to find $\phi_{2}$ we obtain

$$
\phi_{2}=m_{2}\left[\left(\pi_{t}-\bar{\pi}\right)+\lambda_{3}\left(\left(i_{t-1}-i_{t-1}^{*}\right)-\left(\pi_{t}-\pi_{t}^{*}\right)-\varphi_{t-1}\right)\right]+n_{2} x_{t}
$$

where

$$
m_{2} \equiv-\frac{1-\beta(1-\beta \delta)}{\sigma k-\beta \gamma[1-\beta(1-\beta \delta)]} ; \quad n_{2} \equiv \frac{\sigma \lambda_{1}}{\sigma k-\beta \gamma[1-\beta(1-\beta \delta)]}
$$

Now, from (A3) we can solve for $\phi_{1}$ which when equalized with the expression in (A5) and reorganized, generates:

$$
\begin{aligned}
\pi_{t}-\bar{\pi}= & \frac{\beta \lambda_{4}\left[E_{t} i_{t+1}-i_{t}-\lambda_{3}\left(i_{t-1}-i_{t-1}^{*}-\left(\pi_{t}-\pi_{t}^{*}\right)-\varphi_{t-1}\right)\right]}{\sigma m_{1}} \\
& -\frac{\lambda_{4}\left(i_{t}-i_{t-1}\right)}{\sigma m_{1}}
\end{aligned}
$$

From (A4) we can solve for $e_{t}$, in which the values of $\phi_{1}$ and $\phi_{2}$ are replaced to obtain

$$
\begin{aligned}
e_{t}= & e^{n}+\frac{\alpha_{1} m_{1}+\alpha_{2} m_{2}}{\lambda_{2}}\left[\pi_{t}-\bar{\pi}+\lambda_{3}\left(i_{t-1}-i_{t-1}^{*}-\left(\pi_{t}-\pi_{t}^{*}\right)-\varphi_{t-1}\right)\right] \\
& +\frac{\alpha_{1} n_{1}+\alpha_{2} n_{2}}{\lambda_{2}} x_{t}
\end{aligned}
$$

Replacing $\pi_{t}-\bar{\pi}$ from Equation (A10) in (A11) we obtain a simple expression that enables reduction of the four first-order conditions (A1), (A2), (A3) and (A4) in a single equation without the endogenous variables $\phi_{1}$ and $\phi_{2}$ : 


$$
\begin{aligned}
e_{t}= & e^{n}+\frac{\alpha_{1} m_{1}+\alpha_{2} m_{2}}{\lambda_{2}}\left[\left(\frac{\beta \lambda_{4}\left(E_{t} i_{t+1}-i_{t}-\lambda_{3}\left(i_{t-1}-i_{t-1}^{*}\right)\right.}{\sigma m_{1}}\right.\right. \\
& \left.+\frac{\beta \lambda_{4}\left(-\left(\pi_{t}-\pi_{t}^{*}\right)-\varphi_{t-1}\right)-\lambda_{4}\left(i_{t}-i_{t-1}\right)}{\sigma m_{1}}\right) \\
& +\lambda_{3}\left(\left(i_{t-1}-i_{t-1}^{*}\right)-\left(\pi_{t}-\pi_{t}^{*}\right)-\varphi_{(t-1)}\right]+\frac{\alpha_{1} n_{1}+\alpha_{2} n_{2}}{\lambda_{2}} x_{t}
\end{aligned}
$$

From Equation (3) we can solve for $E_{t} \pi_{t+1}$, which is inserted in (2) and then inserted in (A12) which generates the structural optimal Taylor rule that has as its reduced form Equation (12):

$$
\begin{aligned}
i_{t}= & \frac{1}{\Gamma}\left[r^{n}+\left(\frac{\alpha_{1}}{\sigma}-\frac{\alpha_{2}}{\beta}\right) e^{n}\right]+\frac{E_{t} x_{t+1}}{\sigma \Gamma}+\frac{1}{\Gamma}\left\{\left(\frac{\alpha_{1}}{\sigma}-\frac{\alpha_{2}}{\beta}\right)\right. \\
& {\left.\left[\frac{\alpha_{1} n_{1}+\alpha_{2} n_{2}}{\lambda_{2}}-\frac{\alpha_{1} m_{1}+\alpha_{2} m_{2}}{\lambda_{2}} \frac{n_{1}}{m_{1}}\right]-\left(\frac{k}{\beta}+\frac{1}{\sigma}\right)\right\} x_{t} } \\
& +\frac{\delta}{\sigma \Gamma} x_{t-1}+\left(\frac{1}{\beta \Gamma}+\frac{\lambda_{3}\left(\beta+\sigma m_{1}\right)}{\Gamma}\left(\frac{\alpha_{1}}{\sigma}-\frac{\alpha_{2}}{\beta}\right) \frac{\alpha_{1} m_{1}+\alpha_{2} m_{2}}{\sigma m_{1} \lambda_{2}}\right) \pi_{t} \\
& -\frac{\gamma}{\beta \Gamma} \pi_{t-1}+\frac{\delta^{*}}{\sigma \Gamma} x_{t}^{*}-\frac{\lambda_{3}\left(\beta+\sigma m_{1}\right)}{\Gamma}\left(\frac{\alpha_{1}}{\sigma}-\frac{\alpha_{2}}{\beta}\right) \frac{\alpha_{1} m_{1}+\alpha_{2} m_{2}}{\sigma m_{1} \lambda_{2}} \pi_{t}^{*} \\
& +\frac{\lambda_{3}\left(\beta+\sigma m_{1}\right)}{\Gamma}\left(\frac{\alpha_{1}}{\sigma}-\frac{\alpha_{2}}{\beta}\right) \frac{\alpha_{1} m_{1}+\alpha_{2} m_{2}}{\sigma m_{1} \lambda_{2}} i_{t-1}^{*} \\
& +\frac{\lambda_{3}\left(\beta+\sigma m_{1}\right)}{\Gamma}\left(\frac{\alpha_{1}}{\sigma}-\frac{\alpha_{2}}{\beta}\right) \frac{\alpha_{1} m_{1}+\alpha_{2} m_{2}}{\sigma m_{1} \lambda_{2}} \varphi_{t-1} \\
& +\frac{\beta \lambda_{4}}{\Gamma}\left(\frac{\alpha_{1}}{\sigma}-\frac{\alpha_{2}}{\beta}\right) \frac{\alpha_{1} m_{1}+\alpha_{2} m_{2}}{\sigma m_{1} \lambda_{2}} E_{t} i_{t+1} \\
& +\frac{\lambda_{4}-\lambda_{3}\left(\beta+\sigma m_{1}\right)}{\Gamma}\left(\frac{\alpha_{1}}{\sigma}-\frac{\alpha_{2}}{\beta}\right) \frac{\alpha_{1} m_{1}+\alpha_{2} m_{2}}{\sigma m_{1} \lambda_{2}} i_{t-1}+\frac{\varepsilon_{1 t}}{\sigma \Gamma}-\frac{\varepsilon_{2 t}}{\beta \Gamma}
\end{aligned}
$$

where structural parameters are shown explicitly associated with the variables and the parameter $\Gamma$ is defined as follows:

$$
\Gamma \equiv\left[1+\left(\frac{\alpha_{1} m_{1}+\alpha_{2} m_{2}}{\sigma m_{1} \lambda_{2}}\right)\left(\frac{\alpha_{1}}{\sigma}-\frac{\alpha_{2}}{\beta}\right) \lambda_{4}(1+\beta)\right]
$$




\section{Linear dynamic system}

We can rewrite the model recursively as a discrete linear dynamic system to show the existence and uniqueness of a steady state. Under $\varepsilon_{1 t}=\varepsilon_{2 t}=0$ the model can be written as a second-order, nonhomogeneous linear system as follows:

$$
A_{0} Z_{t+1}=A Z_{t}+B Z_{t-1}+C
$$

where $A_{0}, A, B$ are $8 \times 8$ matrices while $C$ is an $8 \times 1$ matrix, and we define

$$
Z_{t+1}=\left[\begin{array}{c}
E_{t} x_{t+1} \\
E_{t} \pi_{t+1} \\
E_{t} i_{t+1} \\
E_{t} e_{t+1} \\
E_{t} x_{t+1}^{*} \\
E_{t} \pi_{t+1}^{*} \\
E_{t}{ }_{t+1}^{*} \\
E_{t} \varphi_{t+1}
\end{array}\right] .
$$

A convenient way to analyze the system is to transform it into a non homogenous first order linear system. For this, define $Z_{t+1} \equiv Y_{t}$ such that $Z_{t+2} \equiv Y_{t+1}$ and we can rewrite the second-order system (A14) as

$$
H W_{t+1}=M W_{t}+N
$$

where $W_{t}=\left[\begin{array}{c}Y_{t} \\ Z_{t}\end{array}\right], H=\left[\begin{array}{cc}A_{0} & 0 \\ 0 & I_{8}\end{array}\right], M=\left[\begin{array}{cc}A & B \\ I_{8} & 0\end{array}\right], N=\left[\begin{array}{c}C \\ 0\end{array}\right]$.

Note that $I_{8}$ is an $8 \times 8$ identity matrix, $W$ is a $16 \times 1$ vector, $H$, and $M$ are $16 \times 16$ matrices and $N$ is a $16 \times 1$ vector.

\section{Existence and uniqueness of the steady state}

Proposition 3. The dynamic system (A15) has a unique steady state if $\sigma k=1-\beta(1-\beta \delta), 1>\beta+\gamma, \gamma \in(-1,1), 0>\alpha_{1} \beta^{2} \gamma>\alpha_{2} \sigma$, $\lambda_{2} \leq \beta \lambda_{3}^{2}$ and 
$\lambda_{1}<\min \left\{\frac{k^{2}\left[\lambda_{3}(2-\beta \gamma)\right]+1}{\beta \gamma(1-\beta-\gamma)}, \frac{k(1-\beta \delta)(1-\beta)\left(\lambda_{3}(2-\beta \gamma)+1\right)}{(1-\gamma) \sigma \beta \gamma}\right\}$

Proof: To prove this result, note that in steady state we have $W_{t}=\bar{W}$ for all $t$ in (A15). Therefore, to prove the existence and uniqueness of the steady state of the dynamic system, we must find the conditions that guarantee that $[H-M]^{-1}$ exists such that a steady state exists in the sense $\bar{W}=[H-M]^{-1} N$ exists. A sufficient condition such that $\bar{W}$ exists is that $\operatorname{det}[H-M] \equiv|H-M| \neq 0$. Note that $H-M=\left[\begin{array}{cc}A_{0} & 0 \\ 0 & I_{8}\end{array}\right]-\left[\begin{array}{cc}A & B \\ I_{8} & 0\end{array}\right]=\left[\begin{array}{cc}A_{0}-A & -B \\ -I_{8} & I_{8}\end{array}\right]$.

Through the formula of the determinant for a partitioned ${ }^{24}$ matrix it follows that

$|H-M|=\left|I_{8}\right| \cdot\left|A_{0}-A-B\right|$

Therefore, we consider developing the determinant of $\left|A_{0}-A-B\right|$.

This determinant can be obtained using the cofactors method on the rows or columns with the greatest quantity of zeros which leads to obtaining $\left|A_{0}-A-B\right|=G \cdot|S|$, where $G$ is the scalar given by

$G \equiv\left(\rho_{\varphi, 1}+\rho_{\varphi, 2}-1\right)\left(\rho_{x, 1}+\rho_{x, 2}-1\right)\left(\rho_{\pi, 1}+\rho_{\pi, 2}-1\right)$.

and $S \equiv\left[\begin{array}{llll}s_{1} & s_{2} & s_{3} & s_{4}\end{array}\right]$, is a $4 \times 4$ matrix where

$$
s_{1}=\left[\begin{array}{c}
\delta-k \frac{\sigma}{\beta} \\
\frac{k}{\beta} \\
-\frac{\sigma n_{1}}{\beta \lambda_{4}} \\
-\frac{1}{\lambda_{2}}\left(n_{1} \alpha_{1}+n_{2} \alpha_{2}\right)
\end{array}\right], s_{2}=\left[\begin{array}{c}
\frac{\sigma}{\beta}(1-\gamma) \\
1-\frac{1}{\beta}(1-\gamma) \\
-\frac{\sigma m_{1}}{\beta \lambda_{4}}\left(\lambda_{3}\left(\frac{1}{\sigma} \frac{\beta}{m_{1}}\right)+1\right) \\
-\left(\begin{array}{c}
m_{1} \alpha_{1} \\
+m_{2} \alpha_{2}
\end{array}\right)\left(-\frac{\lambda_{3}}{\lambda_{2}}\right)
\end{array}\right],
$$

24. Let A be a matrix that can be partitioned into four submatrices $A=\left[\begin{array}{ll}A_{11} & A_{12} \\ A_{21} & A_{22}\end{array}\right]$. Hence, the determinant of A is given by $|A|=\left|A_{22}\right| \cdot\left|A_{11}-A_{12}\left[A_{22}\right]^{-1} A_{21}\right|$. 


$$
\begin{aligned}
& s_{3}=\left[\begin{array}{c}
-\sigma \\
0 \\
\frac{\sigma m_{1}}{\beta \lambda_{4}}\left(-\lambda_{3}+\frac{\lambda_{4}-\beta \lambda_{3}}{\sigma m_{1}}\right)-\frac{\beta+1}{\beta}+1 \\
1
\end{array}\right], s_{4}=\left[\begin{array}{c}
-\alpha_{1}-\frac{\sigma \alpha_{2}}{\beta} \\
\frac{\alpha_{2}}{\beta} \\
0 \\
1
\end{array}\right] \\
& |S|=\left(\frac{\sigma \alpha_{2}}{\beta(1-\beta \gamma) \lambda_{4}}\right)\left[\left(\frac{\beta^{2} \gamma \lambda_{1}}{k(1-\beta \gamma)}\right)\left(\frac{\alpha_{1}}{\sigma}-\frac{\alpha_{2}}{\beta}\right)\left(\frac{1}{\beta \lambda_{3}}-\frac{\lambda_{3}}{\lambda_{2}}\right)\right. \\
& +\left(\frac{\lambda_{1}}{k \lambda_{2}}\right)\left(\frac{\alpha_{2} \sigma-\alpha_{1} \beta^{2} \gamma}{\sigma(1-\beta \gamma)}\right)\left(\lambda_{3}(2-\beta \gamma)+1\right)^{1} \\
& +\left[\frac{\sigma}{\beta(1-\beta \gamma) \lambda_{4}}+\left(\alpha_{1}+\frac{\sigma \alpha_{2}}{\beta}\right)\left(\frac{\lambda_{3}}{\lambda_{2}(1-\beta \gamma)^{2} \lambda_{4}}\right)\left(\frac{\alpha_{1}}{\sigma}-\frac{\alpha_{2}}{\beta}\right)_{]}^{]}\right. \\
& {\left[k\left(\lambda_{3}(2-\beta \gamma)+1\right)-(1-\beta-\gamma)\left(\frac{\beta \gamma \lambda_{1}}{k}\right)\right]} \\
& +\left(\frac{\lambda_{3}}{\lambda_{2}}\right)\left(1+\frac{1}{1-\beta \gamma}\right)\left(\frac{\alpha_{2}}{\beta(1-\beta \gamma)}\right)\left[(1-\beta \gamma)(1-\beta)\left(\frac{\alpha_{1}}{\sigma}-\frac{\alpha_{2}}{\beta}\right)\left(\frac{1}{\beta \lambda_{3}}-\frac{\lambda_{3}}{\lambda_{2}}\right)\right. \\
& +\left(\frac{\lambda_{1}}{\lambda_{2}}\right)\left(\frac{\alpha_{2} \sigma-\alpha_{1} \beta^{2} \gamma}{\beta}\right)(1-\gamma)_{1}^{1}+\left(\frac{\alpha_{2} \lambda_{3}}{\lambda_{4}(1-\beta \gamma)^{2} \beta \lambda_{2}}\right)\left(\frac{\alpha_{1}}{\sigma}-\frac{\alpha_{2}}{\beta}\right) \\
& {\left[\left(\frac{\sigma \beta \gamma \lambda_{1}}{k}\right)(1-\gamma)-(1-\beta \delta)(1-\beta)\left(\lambda_{3}(2-\beta \gamma)+1\right)_{]}^{1}\right.} \\
& +\left(\frac{\lambda_{3}}{\lambda_{4}(\beta)^{2}}\right)\left(1+\frac{1}{1-\beta \gamma}\right)[(1-\beta \delta)(1-\beta)(1-\beta-\gamma)- \\
& (1-\beta(1-\beta \delta))(1-\gamma)]-\left(\frac{\sigma \lambda_{3}}{(1-\beta \gamma) \lambda_{4}}\right)\left(1+\frac{1}{1-\beta \gamma}\right)\left(\frac{\alpha_{1}}{\sigma}+\frac{\alpha_{2}}{\beta}\right) \\
& {\left[k\left(\frac{\alpha_{1}}{\sigma}-\frac{\alpha_{2}}{\beta}\right)\left(\frac{1}{\beta \lambda_{3}}-\frac{\lambda_{3}}{\lambda_{2}}\right)+\left(\frac{\lambda_{1}}{\beta k \lambda_{2}}\right)\left(\frac{\alpha_{2} \sigma-\alpha_{1} \beta^{2} \gamma}{\sigma}\right)(1-\beta-\gamma)\right]}
\end{aligned}
$$

Under the assumptions given by Equations (8) and (9) in the set-up of the model we obtain $G \neq 0$ and therefore we only need to find the conditions that yield $|S| \neq 0$. Thus, we use the cofactors method to develop the determinant of $S$ by its third column $s_{3}$ which yields the determinant of $S$ in Equation (A16) after replacing the constants $m_{i}$ and $n_{i}$ for $i=1,2$ from equations (A6) and (A9) as well as heavy manipulation. All terms are strictly negative under the proposition's assumptions; therefore we conclude that the determinant of $\mathrm{S}$ is negative and hence different from zero, implying that there is a steady state of the linear dynamic system (A15). The same linearity of the system implies that the steady state is unique. 


\section{APPENDIX B}

\section{Unit root test for inflation}

Equation (B1) bellow presents, for the inflation rate, the auxiliary regression of the augmented Dickey-Fuller test, under a Markov switching process. In this case, the coefficients and variances are state dependent; in other words, they are governed by a stochastic and unobserved state variable $S_{t} \in\{0,1\}$ :

$$
\Delta \pi_{t}=\rho_{S_{t}} \pi_{t-1}+C_{S_{t}}+\theta_{S_{t}} t+\sum_{j=1}^{K} \eta_{j S_{t}} \Delta \pi_{t-j}+v_{t}
$$

This state variable follows a Markov order process, one whose probabilities of transition are defined by: $\operatorname{Pr}\left[S_{t}=0 \mid S_{t-1}=0\right]=p$, $\operatorname{Pr}\left[\mathrm{S}_{t}=1 \mid S_{t-1}=1\right]=q, \operatorname{Pr}\left[\mathrm{S}_{t}=1 \mid S_{t-1}=0\right]=1-p$ and $\operatorname{Pr}\left[\mathrm{S}_{t}=0 \mid S_{t-1}=1\right]=1-q$.

The unit root test is based on the $t$ statistic corresponding to the coefficient $\rho_{S_{t}}$ associated with the variable $\pi_{t-1}$. The null hypothesis is the existence of the unit root, that is, $\mathrm{H}_{0}: \rho_{S_{t}}=0$ versus the alternative $\mathrm{H}_{1}: \rho_{S_{t}}<0$, that is, a stationary process. It should be pointed out that this statistic is calculated as the ratio of the estimated coefficient and its standard deviation, derived from the negative inverse of the Hessian matrix of the likelihood function evaluated at the maximum (see Camacho, 2010 and Hall et al., 1999). The construction of the unit root test for the existence of a unit root in the inflation rate, where there are two economic regimes during the period of study, requires taking the following steps:

1) Equation (B1) must be estimated under the null hypothesis and its disturbances must be grouped into two exclusive subsets. The subset assignment scheme is carried out through the filtered probabilities of transition.

a) Subset $\mathbf{A}_{1}$ corresponds to the residuals associated with regime 0 .

b) Subset $\mathbf{A}_{2}$ corresponds to the residuals associated with regime 1 . where $\mathbf{A}_{1} \cap \mathbf{A}_{2}=\varnothing$.

2) $\mathrm{A}$ number $\mathrm{B}$ of vectors $\mathbf{A}^{b}$ are generated, where $b=1, \ldots, \mathrm{B}$ are disturbances of the same sample size. With that objective, 
we construct subvectors $\mathbf{A}_{1}{ }^{b}$, and $\mathbf{A}_{2}{ }^{b}$, where $b=1, \ldots, \mathrm{B}$ under sampling with repetition of subsets $\mathbf{A}_{1}$ and $\mathbf{A}_{2}$, respectively. Respecting the position of the state associated with the filtered probabilities, the union of the subvectors results in the vector sought out, $\mathbf{A}^{b}$ for $b=1, \ldots, \mathrm{B}$.

3) A dichotomous state variable $S^{*}(t)$ is generated that is associated with the states suggested by the series of filtered transition probabilities.

4) $\mathrm{B}$ realizations are generated of variable $\pi^{b}, b=1, \ldots, \mathrm{B}$ using the disturbances in step 2.

For all $b=1, \ldots, \mathrm{B}$

$$
\begin{aligned}
\Delta \pi_{t}^{b}= & C_{0}\left(1-S_{t}^{*}\right)+C_{1} S_{t}^{*}+\theta_{0}\left(1-S_{t}^{*}\right)+\theta_{1} S_{t}^{*} t \\
& +\sum_{j=1}^{K}\left[\eta_{j 0}\left(1-S_{t}^{*}\right) \Delta \pi_{t-j}+\eta_{j 1} S_{t}^{*} \Delta \pi_{t-j}\right]+e_{t}^{b}
\end{aligned}
$$

5) Equation (B1) is estimated for each of the $\Delta \pi^{b}{ }_{t}$ and the $t$-statistics associated with the coefficient that accompanies $\pi_{t-1}^{b}$ are stored in a vector of size $B \times 1$. It should be pointed out that the $t$-statistic is constructed with the standard deviations from the negative of the inverse of the Hessian matrix associated with the optimization procedure that maximizes the likelihood function.

6) The $p$-value of the unit root test for each state corresponds to the percentage of $t$ statistics found below the original statistic $t_{\varrho}$, Equation (B1). 
